\title{
The Dynamic Effects of Disinflation Policies
}

\author{
Fabrice Collard \\ University of Toulouse (CNRS-GREMAQ and IDEI) \\ Patrick Fève* \\ University of Toulouse (GREMAQ and IDEI) \\ and Banque de France (Research Division) \\ Julien Matheron \\ Banque de France (Research Division)
}

March 2007

\begin{abstract}
This paper investigates the effects of disinflation policies on key macroeconomic variables. Using postwar US data and episode techniques, we identify disinflation shock as shocks that drive the inflation rate to a lower level in the long-run. We find that in the immediate aftermath of a disinflation policy, the economy enters in a persistent recession. The inflation rate increases above its long-run level and exhibits a positive hump-shaped response. A similar pattern is found for the nominal interest rate, which responds even more strongly in the short-run. We then show that the standard new Keynesian model fails to account for macroeconomic dynamics in disinflationary times. On the contrary a deep habit version of the model successfully accounts for the effects of disinflation policies.
\end{abstract}

Keywords: Disinflation policies, Deep Habits, New Keynesian Models, Countercyclical Markups.

JEL Class: E31, E32, E52.

\footnotetext{
*Address: GREMAQ-Université de Toulouse I, manufacture des Tabacs, bât. F, 21 allée de Brienne, 31000 Toulouse. emails: patrick.feve@univ-tlse1.fr. We would like to thank Larry Christiano and Martial Dupaigne for helpful comments. We also thank participants at various seminars. The traditional disclaimer applies. The views expressed herein are those of the authors and not necessary those of the Banque de France.
} 


\section{Introduction}

Disinflation episodes are stressful times for modern developed economies and are usually perceived as one - not to say the dominant - cause of recessions. For instance, Ball (1994) argues that each of the downturns that affected the US economy in the early 1970s, mid 1970s and early 1980s coincided with falling inflation caused by monetary tightening. Likewise, many observers hold the Volcker disinflation responsible for the most severe contraction in post World War II U.S. history. From a quantitative point of view, the cumulative loss in output consecutive to a disinflation policy - also known as the sacrifice ratio - is almost always found to be sizable. ${ }^{1}$ Disinflation recessions cannot be ignored and are major events that any monetary model should account for. This paper addresses this issue.

A whole strand of the literature, relying on a sticky price-sticky wage version of the new Keynesian model, have attempted to account for the effects of disinflation policies on aggregate dynamics. For instance, Ball (1995) proposes a model of a disinflation policy and shows that it can deliver qualitatively satisfactory results. More recently Erceg and Levin (2003) and Bordo, Erceg, Levin and Michaels (2006) show that a calibrated version of a new Keynesian model can provide a good representation of disinflation episodes. Common to all these papers is their departure from the standard model by assuming imperfect information in the private sector. For instance, a key element of the last two papers is that agents are imperfectly informed about the stance of monetary policy. This assumption is critical for the result. Indeed in a full information version of the model, although prices (and plausibly wages) are sticky, inflation remains so volatile that monetary policy can drive the inflation rate down to zero without creating any loss in output. Hence, absent imperfect information on the monetary policy stance, the model of the new Keynesian Phillips curve creates a "Disinflation without Recession" (see Phelps (1978)), which is at odds with the evidence. To borrow Gregory Mankiw's provocative assertion in his Harry Johnson Lecture at the 2000 meeting of the Royal Economic Society "although the new Keynesian Phillips curve has many virtues, it also has one striking vice: It is completely at odds with the facts."

The main contribution of this paper is twofold. On the empirical side, we document

\footnotetext{
${ }^{1}$ For example, Ball (1994) reports sacrifice ratios of, respectively, $2.94 \%$ and $1.83 \%$ for the $1969: 4-$ 1971:4 and the 1980:1-1983:4 disinflations. Erceg and Levin (2003), resorting to similar techniques as in Ball (1994), report a sacrifice ratio of 1.7\%. Cecchetti (1994) and Cecchetti and Rich (2001) find estimates ranging from $1.3 \%$ to almost $10 \%$ using Vector AutoRegression techniques. Recent studies (see Filardo (1998), Owyang and Ramey (2004), Francis and Owyang (2005)) have put the emphasis on potential non-linearities in the sacrifice ratio, but still find that disinflation policies are associated with cumulative output losses greater than $1 \%$.
} 
the dynamic effects of disinflation policies on the main US aggregate variables. On the theoretical side, we show that the inability of a full information version of the standard new Keynesian model to account for disinflations stems from the modeling of the real side of the model. Once the real side properly refined, the full information version of the standard model is found to generate an empirically plausible recession in the aftermaths of a disinflation policy.

In order to isolate the specific features of disinflation episodes, we first present an empirical analysis of anti-inflationary policies in the post-World War II US economy. We do so by resorting to episode techniques advocated by Romer and Romer (1989) and Romer and Romer (1994) and more recently applied to fiscal policy shocks by Edelberg, Eichenbaum and Fisher (1999), Burnside, Eichenbaum and Fisher (2004) and Eichenbaum and Fisher (2005). A disinflation episode is defined as an attempt from the Federal Reserve to create a recession in order to reduce inflation. An advantage of this approach is that the response of aggregate variables to a disinflation shock can be recovered without the need to specify a particular monetary policy rule. We estimate a Vector AutoRegressive (VAR) model with episodes for the post-World War II US economy. The dynamic effects of a disinflation policy is simply obtained as the responses of aggregates to these episodes. ${ }^{2}$ We find that a disinflation policy immediately throws the economy into a persistent recession which reaches its trough after 16 quarters. The inflation rate increases very little on impact but keeps increasing during 4 quarters and eventually converges to a lower level in the longrun. Inflation therefore displays a hump-shaped pattern that indicates that disinflation policy are, paradoxically, accompanied by an increase in the inflation rate in the shortrun. In other words, successful disinflation policies require that the central bank tolerate loose inflation targeting in the short-run. ${ }^{3}$ The behavior of the nominal interest rate is consistent with the common view about disinflation policies. It exhibits a positive humpshaped pattern in the short-run corresponding to a tighter monetary policy as witnessed by the drop in money growth. To complement our study, we conduct some robustness analysis. In particular we investigate the important issue of identification of disinflation episodes. Our experiments show that as soon as we move away from the selected episodes, the dynamic responses of aggregate variables to shocks to the perturbed episodes are dramatically affected by a change in the date of episodes. Second, we investigate the robustness of the preceding patterns to changes in the specification of the VAR model -

\footnotetext{
${ }^{2}$ The dummy variables that capture episodes are found not to be Granger-caused by past values of the variables included in the VAR. In other words, these dummies can be interpreted as exogenous shocks, which legitimates our exercise.

${ }^{3}$ Such a behavior resembles the so-called price puzzle identified in the face of transitory monetary policy shocks (see Sims (1992) and Eichenbaum (1992)). We however show that this behavior of inflation is robust to various specifications of the VAR model which are known to eliminate the price puzzle in the context of stationary monetary policy shocks.
} 
by relaxing long-run restrictions, and adding or altering some variables - or changes in the identification procedure used to reveal disinflation shocks. Our results indicate that the previous patterns are indeed robust.

In a second step we attempt to tackle explicitly the challenging problem of accounting for the effects of a disinflation with a theoretical model. We propose a fully fledged DSGE model of the new Keynesian Phillips curve and assess its ability to account for the dynamic responses we obtained in the empirical analysis. The model that we construct has two key features. First, it embeds most of the main building blocks of new Keynesian models. In particular, it features sticky prices (wages), habit formation, adjustment costs, working capital and variable capital utilization. Second the real side of the model slightly departs from the benchmark new Keynesian model (Rotemberg and Woodford (1997), Christiano, Eichenbaum and Evans (2005), Altig, Christiano, Eichenbaum and Linde (2005) or Smets and Wouters (2005)) in one critical way. We follow Ravn, Schmitt-Grohe and Uribe (2006) and assume that preferences feature deep habits. In other words, habit persistence bears on each good the household consumes rather than on the consumption bundle as a whole. This last assumption turns out to be critical as it is at the source of the main mechanism driving our results: countercyclical markups. This aspect of the model has already been put forward by Rotemberg and Woodford (1999) as a key feature to account for aggregate dynamics. We then implement a disinflation policy in the model in the form of a permanent change in the inflation target of the central bank. The model is then shown to be consistent with the dynamics reported in the empirical part of the paper. The disinflation policy immediately creates a recession in the economy, the inflation rate and the nominal interest rate both exhibit a positive hump-shaped response in the short-run and eventually converge to their new -lower- steady state level. A version of the model with standard habits fails to account for the facts. The same failure obtains when we consider a version of the model that also features sticky wages, with or without working capital. Therefore, as aforementioned, the deep habit hypothesis is key for the result. The reason is as follows. As explained by Ravn et al. (2006), the price elasticity of demand is an increasing function of aggregate demand in the deep habit model. Therefore, by creating a recession, the disinflation policy yields a decrease in the price elasticity of demand, translating into higher markups, which then turn out to be countercyclical. Therefore prices can increase in the short-run. This triggers a tighter monetary policy that pushes interest rate upward and magnifies the recession. Absent this mechanism the model fails to account for the facts. Our results are found to be robust against alternative specifications of the monetary policy rule used to achieve the disinflation policy. We conclude that, as argued by Christiano et al. (2005), any model that aims at accounting for monetary facts has to possess strong enough real propagation mechanisms that can protract the effects of 
monetary policy.

The paper is organized as follows. Section 2 presents our identification strategy of disinflation policy shocks, discusses our specification choices and the selected dates of the disinflation episodes. It then reports and details our empirical findings. Section 3 assesses the robustness of our empirical findings to changes in the dates of episodes, the specification of the VAR, and the identification strategy. Section 4 presents our theoretical model putting emphasis on the deep habit assumption. Section 5 presents and discusses our theoretical results, highlighting the role played by each assumption for our quantitative findings. A last section offers some concluding remarks.

\section{Empirical Evidence of a Disinflation Shock with Monetary Policy Episodes}

This section first presents our identification strategy of disinflation policy shocks which basically hinges on the episode technique advocated by Romer and Romer (1989). We then discuss our specification choices and the selected dates of the disinflation episodes.

\subsection{Identifying the Effects of a Disinflation Policy Shock}

The identification of monetary policy shocks is largely debated in the literature. Romer and Romer (1989) and Romer and Romer (1994) have proposed to use a narrative approach to isolate episodes in which large exogenous monetary disturbances are observed. Each isolated episode corresponds to an attempt from the Federal Reserve to create a recession in order to reduce inflation. These episodes therefore correspond to disinflation policy shocks and can be used to uncover the effects of such shocks on macroeconomic dynamics. This is the approach we pursue in this paper. As noticed by Christiano, Eichenbaum and Evans (1999), an advantage of Romer and Romer's approach is that the econometrician does not have to formally specify a monetary feedback rule nor to impose a particular identification scheme to recover the responses of the economy. A second advantage of this approach is that the selected episodes correspond to the Fed's intentions to implement an anti-inflationary policy, therefore giving us the opportunity to identify the effects of these specific policies. However, as argued by Shapiro (1994), one of its potential weakness is that the selected dates can reflect aspects of monetary policy that are largely forecastable using macroeconomic variables. An additional weakness of the approach is that only a handful of episodes is available to identify the aggregate effects of a disinflation policy. The first issue will be addressed by means of Granger causality tests. In order to address 
the second issue, we add four additional dates to Romer and Romer's episodes within our sample and pool (once properly scaled) all these episodes into a single dummy variable in an attempt to specify a parsimonious econometric framework.

We use the following procedure. ${ }^{4}$ Let the vector $Z_{t}$ include monetary policy variables as well as other aggregates (output, consumption, inflation rate,...) and define the dummy variables $D_{i, t}, i=1,2, \ldots, n$ where $n$ is the number of selected episodes. $D_{i, t}$ satisfies

$$
D_{i, t}= \begin{cases}1, & \text { if } t=d_{i} \\ 0, & \text { otherwise }\end{cases}
$$

$d_{i}$ denotes the $i$-th element of $d=\left(t_{1}, t_{2}, \ldots, t_{n}\right)^{\prime}$ where $t_{i}(i=1, \ldots, n)$ denotes the date of episode $i$. $Z_{t}$ is assumed to follow a stochastic process of the form

$$
Z_{t}=A_{0}+\sum_{j=1}^{p} A_{1, j} Z_{t-j}+\sum_{j=0}^{q} A_{2, j} \widetilde{D}_{t-j}+u_{t}
$$

where

$$
\widetilde{D}_{t}=\sum_{i=1}^{n} \psi_{i} D_{i, t}
$$

and

$$
\mathrm{E}\left(u_{t}\right)=0 ; \mathrm{E}\left(u_{t} u_{t-s}^{\prime}\right)=\left\{\begin{array}{l}
0, \forall s \neq 0 \\
\Sigma, \text { for } s=0
\end{array}\right.
$$

The scalars $p$ and $q$ in equation (1) are finite integers that determine the number of lags for $Z$ and $D$, respectively. The $\psi_{i}$ 's in equation (2) are positive weights with the normalization $\sum_{i=1}^{n} \psi_{i}=1$. It should then be clear that $\psi_{i}$ is a measure of the relative intensity of episode $i$ and that $\widetilde{D}_{t}$ is a weighted dummy variable that sums up the information contained in the selected episodes. In the sequel, $\widetilde{D}_{t}$ will be referred to as the episodes variable. An advantage of this approach is its parsimony. Furthermore, it facilitates the interpretation of the results as it amounts to assuming that the dynamic effects of all the episodes are identical, while they are free to differ in their intensity. From the estimation of (1), the response of the $j$-th element of $Z$ at time $t+h(h>0)$ to a disinflation shock in period $t$ is obtained from the coefficient on $L^{h}$ in the moving average representation

$$
\left(I-\sum_{j=1}^{p} A_{2, j} L^{j}\right)^{-1} \sum_{j=0}^{q} A_{2, j} L^{j}
$$

where $L$ is the backshift operator.

\footnotetext{
${ }^{4}$ See Edelberg et al. (1999), Burnside et al. (2004), Eichenbaum and Fisher (2005) in the case of government spending and fiscal shocks.
} 


\section{$2.2 \quad$ Data and Episodes}

Model (1) is estimated using US quarterly data. The sample runs from 1960:1 to 2002:4. As argued in Burnside et al. (2004) the choice of variables in $Z_{t}$ implies a trade-off. On the one hand, we would like to include as many variables as possible. However, this would imply estimating a very large number of parameters in a finite sample, thus yielding very imprecise estimates of the responses to a disinflation shock. On the other hand, a regression featuring too few variables in $Z_{t}$ could be corrupted by an omitted variable bias. We therefore choose to adopt an intermediate empirical strategy. In our benchmark experiment, $Z_{t}$ includes the following 9 variables: the cyclical component of real output $\left(\widehat{y}_{t}\right)$, the log of the consumption-output ratio $\left(c_{t}-y_{t}\right)$, the log of the investment-output ratio $\left(x_{t}-y_{t}\right)$, the inflation rate $\left(\pi_{t}\right)$, the nominal interest rate $\left(i_{t}\right)$, wage inflation $\left(\pi_{t}^{w}\right)$, a measure of profits $\left(\operatorname{Prof}_{t}\right)$, money growth $\left(\gamma_{M_{2}, t}\right)$ and a wage wedge $\left(\mathrm{ww}_{t}\right)$. The cyclical component of output is obtained as the residual of a regression of the log of real GDP on a constant and a linear trend. ${ }^{5}$ The consumption-output ratio is measured as the ratio of nominal consumption expenditures (including nondurables, services and government expenditures) to nominal GDP. The investment-output ratio is defined as the ratio of nominal expenditures on consumer durables and private investment to nominal GDP. We measure inflation using the growth rate of the GDP deflator, obtained as the ratio of nominal output to real GDP. Wage inflation is measured as the growth rate of hourly compensation in the Non Farm Business (NFB) sector. The nominal interest rate is the Federal fund rate. The rate of profits is defined as the ratio of after tax corporate profits to nominal GDP. Money growth is the growth rate of M2. The wage wedge is defined as the difference between the logs of labor productivity (GDP divided by hours worked in the NFB sector) and the logs of the real wage (hourly compensation in the NFB sector over the GDP deflator). The data are reported in Figure 1. To identify the effects of a permanent disinflation shock, we adopt the following specification for $Z_{t}$ :

$$
Z_{t}=\left(\widehat{y}_{t}, \quad c_{t}-y_{t}, \quad x_{t}-y_{t}, \quad \Delta \pi_{t}, \quad i_{t}-\pi_{t}, \quad \pi_{t}^{w}-\pi_{t}, \quad \operatorname{Prof}_{t}, \quad \gamma_{M_{2}, t}-\pi_{t}, \quad \mathrm{ww}_{t}\right)^{\prime}
$$

Inflation is specified in first differences to a priori allow for a permanent effect of a disinflation policy. Notice that we do not impose any restriction about the sign of the long-run response of inflation. In addition, we impose that the long-run responses of the nominal variables are the same. To investigate the empirical plausibility of this long-run restriction, we test the null hypothesis of a unit root for $i_{t}-\pi_{t}, \pi_{t}^{w}-\pi_{t}$ and $\gamma_{M_{2}, t}-\pi_{t}$ using the Augmented Dickey Fuller (ADF) test. The first difference of each variable is regressed on a constant, the lagged level as well as four lags of the first difference. The ADF test

\footnotetext{
${ }^{5}$ Note that our results are left unaffected if we use alternative definitions of this component.
} 
statistic is equal to -4.32 for the ex-post real interest rate $\left(i_{t}-\pi_{t}\right),-12.17$ for the difference between wage inflation and inflation $\left(\pi_{t}^{w}-\pi_{t}\right)$ and -5.32 for the difference between money growth and inflation $\left(\gamma_{M_{2}, t}-\pi_{t}\right)$. The unit root hypothesis is thus rejected at the 1 percent level for each variable. ${ }^{6}$

For the sample period we consider, the Romer and Romer (1989) episodes are: December 1968; April 1974; August 1978; October 1979. We follow Christiano et al. (1999) by adding the 1966 credit crunch of February 1966 (see Kashyap, Stein and Wilcox (1993)) and the August 1988 episode identified by Oliner and Rudebusch (1996) as the beginning of a monetary contraction. ${ }^{7}$ In addition, we include the end of 1993 and the first quarter of 2000 in our index of monetary contractions. Monetary policy was indeed characterized by noticeable intended increases in the Federal fund rate target in response to inflation pressures at these last two dates. In December 1993, FOMC members considered that a policy change would appropriately signal the Committee's concern about inflation. To reflect this intended policy change, we choose to add 1993:4 as an episode, despite that inflationary pressure effectively appeared in the middle of $1994 .{ }^{8}$ At the February 2000 meeting, the FOMC considered that there was little evidence that demand was coming into line with potential supply, and thus the risks of inflationary imbalances appeared to have risen. The FOMC therefore raised its target for the Federal funds rate and emphasized the risks of remaining on higher inflation pressures. To sum up, we select the following eight episodes

$$
d=(1966: 2,1968: 4,1974: 2,1978: 3,1979: 4,1988: 3,1993: 4,2000: 1)^{\prime}
$$

The weights $\psi_{i}$ are obtained by computing the peak changes in the Federal fund rate following each episode date. These weights are:

$$
\psi=(0.045,0.267,0.055,0.189,0.095,0.145,0.208,0.057)
$$

Out of the eight selected episodes, four of them represent $80 \%$ of the total weight: 1968:4, 1978:4, 1988:3 and 1993:4. Note that the contribution of episode 1968:4 is rather large, since it represents more than $25 \%$ of the weights. These four episodes are of particular interest for our identification strategy because each of them clearly reveals the monetary authorities' intention of taming inflation. As noticed by Romer and Romer (1989), the Federal Reserve decided in 1968:4 to engineer a disinflation despite declines in present and expected growth. A similar policy was conducted in August 1978, when a tight

\footnotetext{
${ }^{6}$ The critical values of the ADF test statistic at 1, 5 and 10 percent significance levels are $-3.49,-2.88$ and -2.57 , respectively.

${ }^{7}$ Romer and Romer (1994) added an episode date around this time in their extended sample.

${ }^{8}$ In Section 3.1, we consider the issue of uncertainty about the dates of episodes and we show that our results are left unaffected by a one quarter (lead and lag) change in the selected time.
} 
monetary policy was maintained despite forecasts of sluggish growth. Likewise, the 1988:3 episode reveals similar concerns of monetary authorities. As reported in Romer and Romer (1994), the discussions about short-term monetary policy at FOMC meetings made explicit reference to "the desirability of making clear that the current rate of inflation was unacceptable" 9 and to a monetary policy tightening as a way "to permit progress to be made in reducing inflation over time". Finally, for the last of these four episodes, the FOMC agreed on the necessity of a prompt tightening move in monetary policy "to provide greater assurance that inflationary pressures in the economy would remain subdued".

Figure 1: Data and Episodes
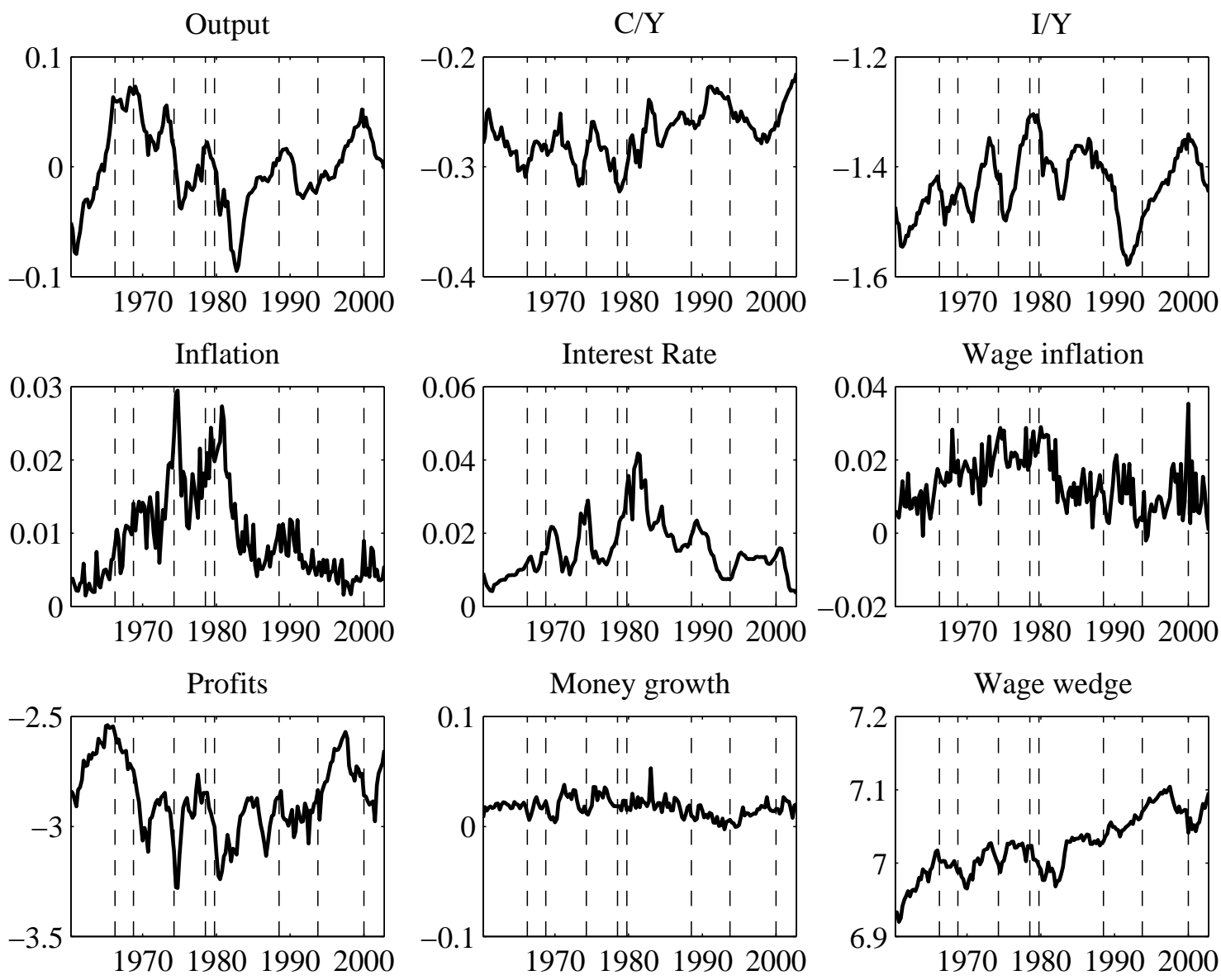

Note: The dashed line correspond to the dates of disinflation episodes. All variables are in logs.

The dates of our episodes are reported in Figure 1 together with actual data. The figure shows that output sharply decreases after each of these dates. This is especially true after the 1968:4, 1979:4, 1988:3 and 2000:1 episodes. Conversely, the output drop appears

\footnotetext{
${ }^{9}$ All quotations are reported in the "Minutes of the Federal Open Market Committee", Federal Reserve Bulletin, various issues.
} 
somewhat moderate after the 1966:2 and 1993:4 episodes. The consumption-output ratio moves in the opposite direction, reflecting the smoothness of consumption. In contrast, the investment-output ratio falls significantly after each episode, with the exception of 1993:4. Inflation decreases in the periods subsequent to the episode dates whereas the Federal fund rate sharply increases after the 1968:4, 1978:3 and 1993:4 episodes. Wage inflation behaves as the rate of inflation, but with a moderate decrease. Interestingly, profits sharply decrease after the credit crunch episode of 1966:2 and the 1978:3-1979:4 episodes. Money growth has an overall pattern similar to those of inflation and wage inflation, i.e. it decreases after the disinflation episodes. Finally, the wage wedge evolves in a way similar to profits and decreases after the 1966:2, 1978:3 and 1979:4 episodes.

\subsection{Empirical Findings}

Given our choice for $Z_{t}$ in (4), we first estimate (1) for the sample period 1960:1 to 2002:4. The scalars $p$ and $q$ in (1) are both set to 4 according to standard criteria. As a first step, we assess the contribution of the episode variables $\widetilde{D}_{t}, \ldots, \widetilde{D}_{t-4}$ in terms of fit. The likelihood ratio test leads us to reject the null hypothesis that $A_{2,0}=A_{2,1}=\cdots=A_{2,4}=0$ in model (1) since the associated statistic is equal to 75.46 with a corresponding $p$-value of $0.3 \%$. Before proceeding any further, it is important to make sure that the episodes variable is not Granger-caused by aggregate variables in $Z_{t}$. Indeed, one important and common criticism addressed to the narrative approach is the predictability of $\widetilde{D}_{t}$ (see Shapiro (1994) and Leeper (1997)) which then questions the exogenous status of $\widetilde{D}_{t}$ in model (1). We therefore follow Leeper (1997) and run Granger causality tests for $\widetilde{D}_{t}$ using both OLS and logistic regressions. The regression includes four lags of all the variables contained in $Z_{t}$. Both tests reject that past values of $Z_{t}$ help predicting disinflation episodes. ${ }^{10} \mathrm{We}$ are therefore immune to the critique put forth by Shapiro (1994) and Leeper (1997). As a second step, the responses of the aggregate variables are computed using equation (3). They are reported in Figure 2. The figure also reports the centered 95 percent confidence interval as computed by standard bootstrap methods, using 1000 draws from the sample residuals. The size of the disinflation shock is normalized such that the inflation rate is 1 point below its initial level in the long-run. Since we impose a long-run restriction on nominal variables, the nominal interest rate, wage inflation, and money growth also converge to the same lower value in the long-run.

The response of output is persistently negative and displays a U-shaped profile that attains

\footnotetext{
${ }^{10}$ In the OLS regression, the Fisher test statistic is 1.02 with a $P$-value of $45.53 \%$ and the Wald test takes a value of 47.02 with $P$-value of $10.34 \%$. The corresponding values for the logistic regression are respectively given by $0.87(P$-value $=67.80 \%)$ and $40.25(P$-value $=28.76 \%)$.
} 
its trough after 16 quarters. Notice that the response is still negative five years after the onset of a disinflation episode. In addition, the negative response of output appears precisely estimated. Consumption and investment display a similar persistent pattern. However, the size of the response differs. Consumption is less responsive than output whereas investment drops sharply. A noticeable finding relates to the response of inflation. Recall that the long-run response of inflation is negative. However, inflation exhibits a positive hump-shaped response in the short-run which reaches its peak 1 year after the disinflation shock. It is also worth noting that the peak in the response of inflation $(+1 \%)$ is about the same size as the overall disinflation $(-1 \%)$. In other words, the disinflation policy is followed by a sizeable increase in inflation. Moreover, this increase is long-lasting as it takes 4 years for the response of inflation to become negative. Interestingly, the nominal interest rate displays a similar pattern. The response is positive and humpshaped, peaking after about 6 periods. The hump pattern of the nominal interest rate is significantly different from zero, as suggested by the narrow confidence interval at the peak value. Notice that the short-run positive response is twice as large as the long-run response. In other words, a disinflation policy which permanently leads to a decline of $4 \%$ per year in the inflation rate in the long-run implies an increase in the nominal interest rate by an amount of $8 \%$ per year in the short-run. The nominal interest rate thus appears very reactive in the short-run after our identified disinflation shock. The response of wage inflation is similar to that of inflation except in the very short-run where the response is negative and small. The disinflation shock also leads to a persistent decline in profits and in the wage wedge. Finally, the response of money growth is in line with intuition as it essentially mirrors that of the nominal interest rate in the short-run. However, money growth follows the inflation rate in the subsequent periods and permanently falls in the long-run. In the sequel, we essentially focus our analysis on the response of those variables that lie at the core of the monetary propagation mechanism: output, inflation, and the nominal interest rate. These variables will be later used as a discriminating device between competing theories of disinflation.

In order to supplement the preceding analysis, we now investigate an alternative way of assessing the historical impact of a disinflation policy on aggregate variables. For each episode, we generate forecasts of $Z_{t}$ using the estimated model. We then run a counterfactual experiment in which we shut down the episode variable. The last exercise then accounts for the dynamics that would have prevailed absent of disinflation shock. Figure 3 reports these forecasts for output, inflation and the nominal interest rate. In each figure, the gray plain line represents actual data, the dark plain line corresponds to the forecast with episode dummies and the dark dashed line is the forecast without the latter. These forecasts are computed for the next twelve quarters following the date 
Figure 2: Response to disinflation episodes
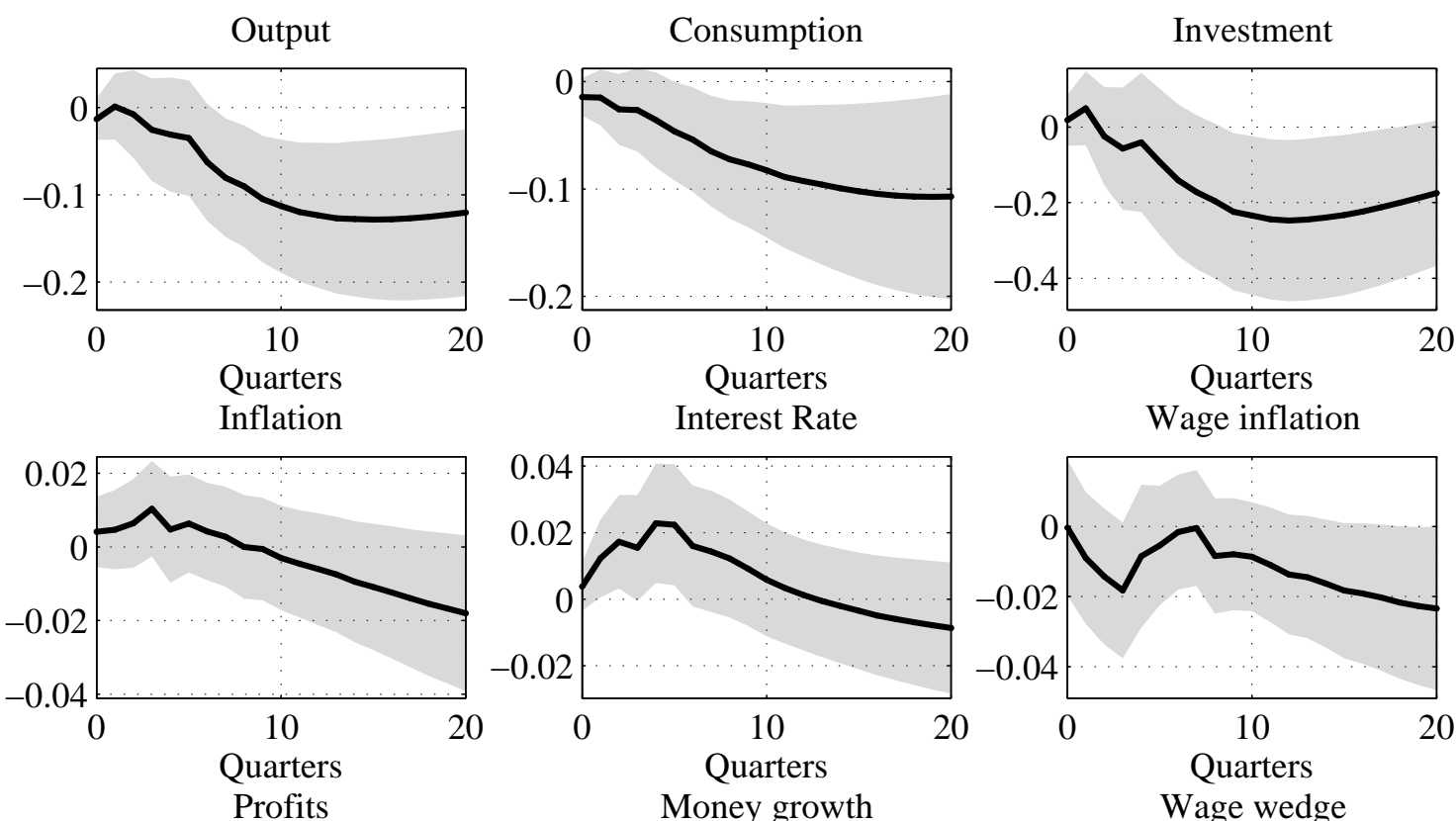

Wage inflation
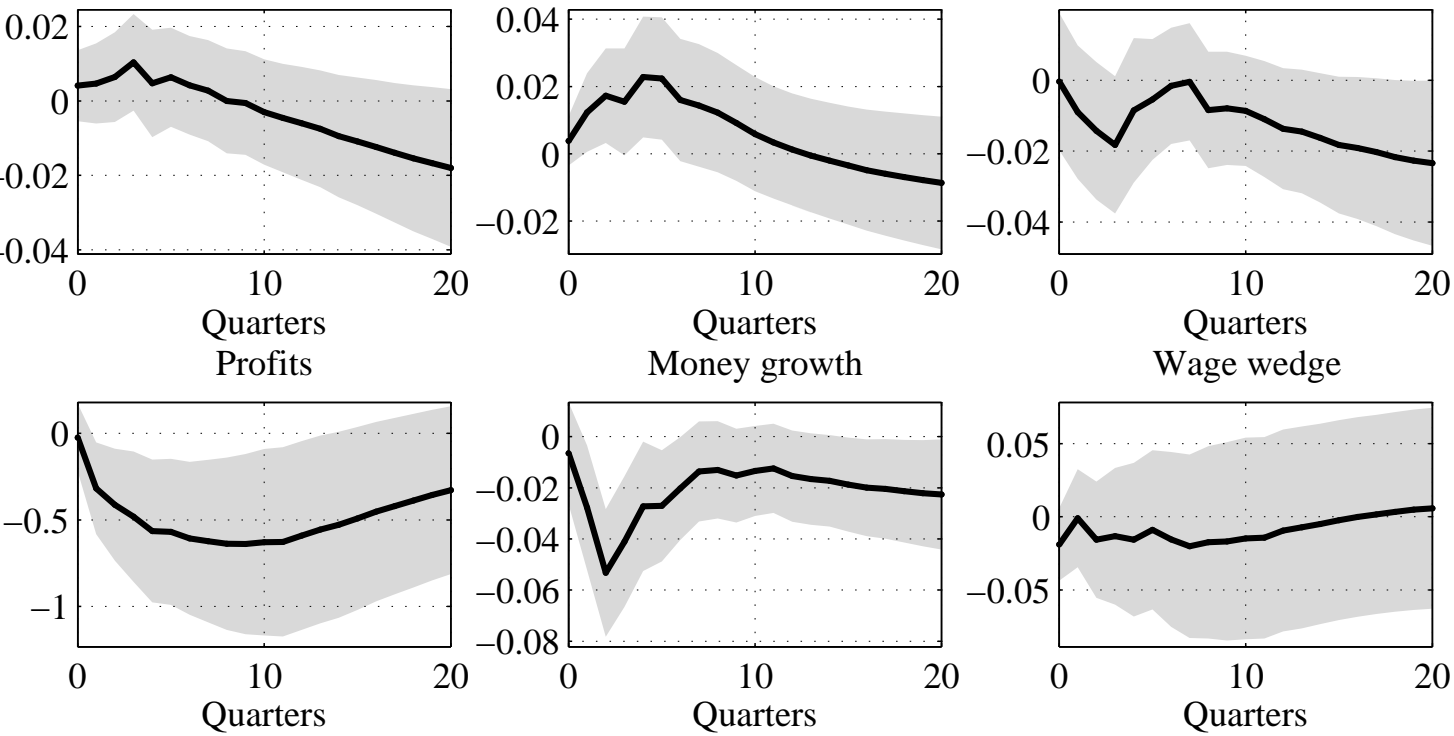

Money growth
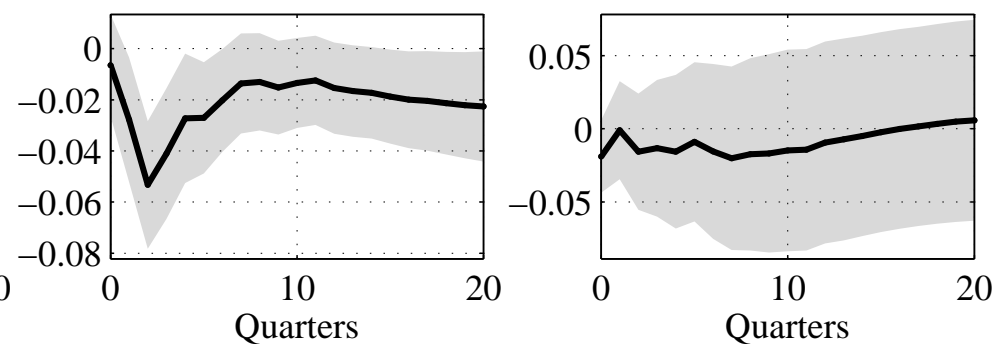
of the episode. Recall that our normalization of $\psi_{i}$ 's implies that the effects of different episodes only differ in their size. Figure 3 does not report the historical decomposition for all the episodes, since the out-of-sample forecasts with dummies only slightly outperform those obtained without dummies for the episodes 1966:1, 1974:2, 1979:4 and 2001:1. ${ }^{11}$. Panels (a)-(d) of Figure 3 display forecasts for the episodes 1968:4, 1978:3, 1988:3 and 1993:4, which are also those which are assigned the highest weight in $\psi$. For all these episodes, the introduction of $\widetilde{D}_{t}$ improves on the forecasts of output and nominal interest rate. Notably, the inclusion of episodes allows for a better fit of (i) the initial increase in the nominal interest rate following each episode and (ii) the decrease in output after the episodes 1968:4, 1978:3 and 1988:3.

\section{Robustness Analysis}

The previous section documented the response of the US economy to a disinflation policy. We now check the robustness of our empirical findings to various modifications. These relate to the dates of episodes, the specification of $Z_{t}$, and the identification strategy.

\subsection{Robustness to the Episodes Dates}

As aforementioned, out of the eight selected episodes, four of them represent $80 \%$ of the total weight: 1968:4, 1978:4, 1988:3 and 1993:4. As a first attempt to check for the robustness of our results, we investigate how the omission of the other four episodes (1966:2, 1974:2, 1978:3 and 2000:1) ought to induce some specification bias. Figure 4 reports the associated IRFs. As can be seen from the figure, the main conclusions of the analysis remain. In the aftermath of the announcement of the disinflation, the economy enters a persistent and profound recession that hits its trough after about 4 years. Inflation first persistently rises to eventually reach its new level. The nominal interest rate displays a similar hump-shaped pattern.

We then investigate the role played by the uncertainty surrounding the actual dates at which disinflation policy shocks occurred in the same model. A simple way to assess the importance of an episode date is to re-estimate the model with different disinflation episodes dates and inspect whether the shape of the response is altered by such a change. Uncertainty about the dates of the episodes does not matter if the response of the economy is only marginally affected by a small perturbation in the selected dates. At the same time, if the response of the economy remains unaltered whichever dates are considered, there

\footnotetext{
${ }^{11}$ These forecasts are reported in Figure 17 in Appendix
} 
Figure 3: Historical decomposition of episodes

(a) 1968:4 episode
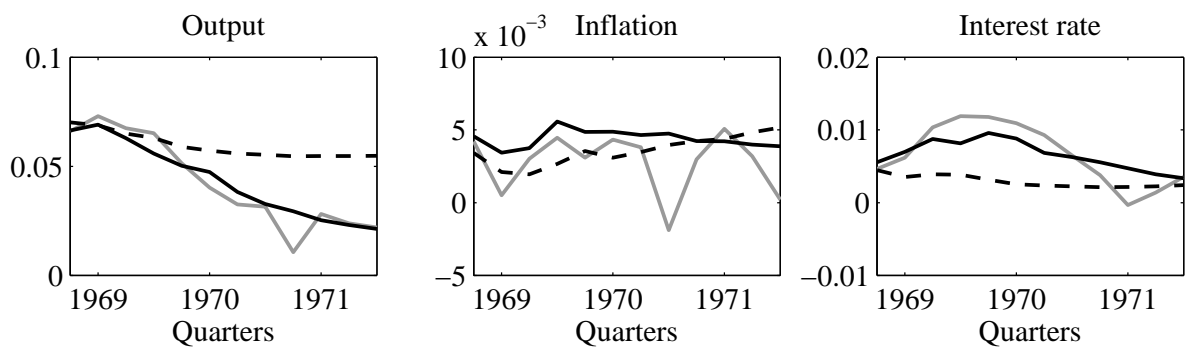

(b) 1978:3 episode
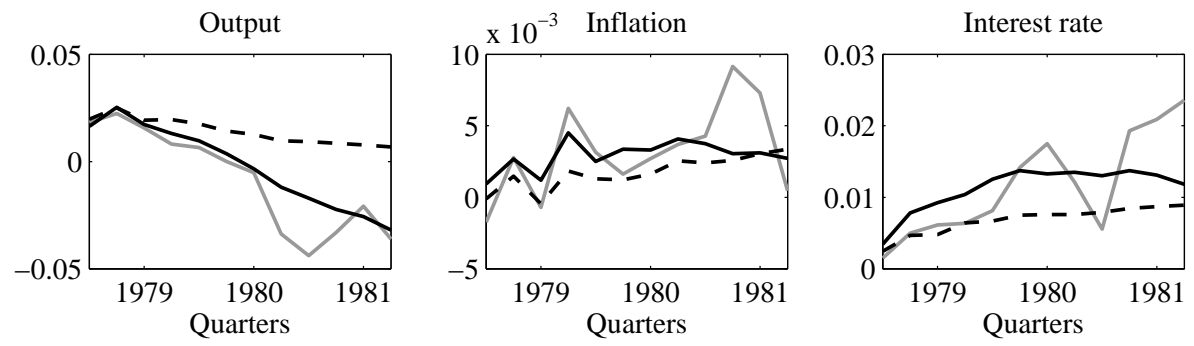

(c) 1988:3 episode
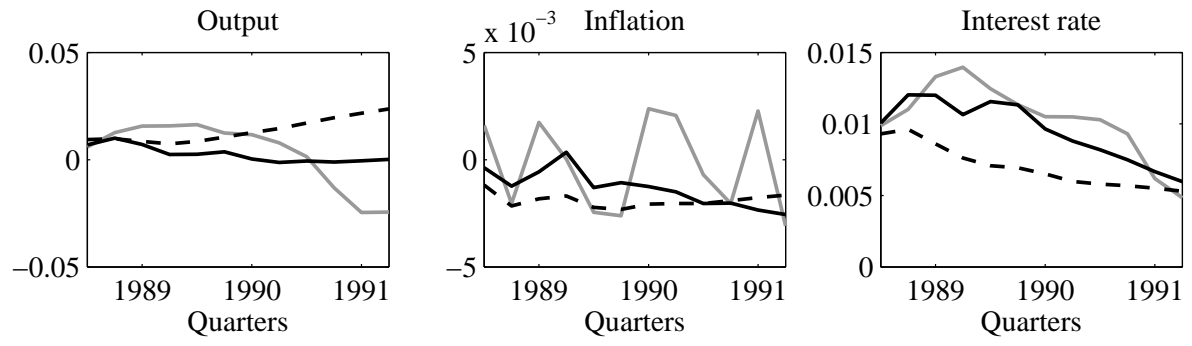

(d) 1993:4 episode
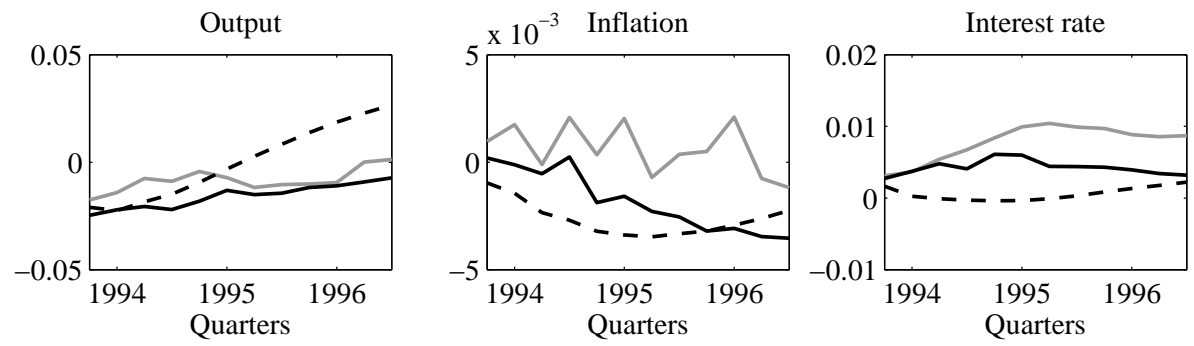

Note: gray plain line: Actual data, dark plain line: Forecast with episode, dark dashed line: Forecast without episode. 
Figure 4: Omitting the unimportant episodes
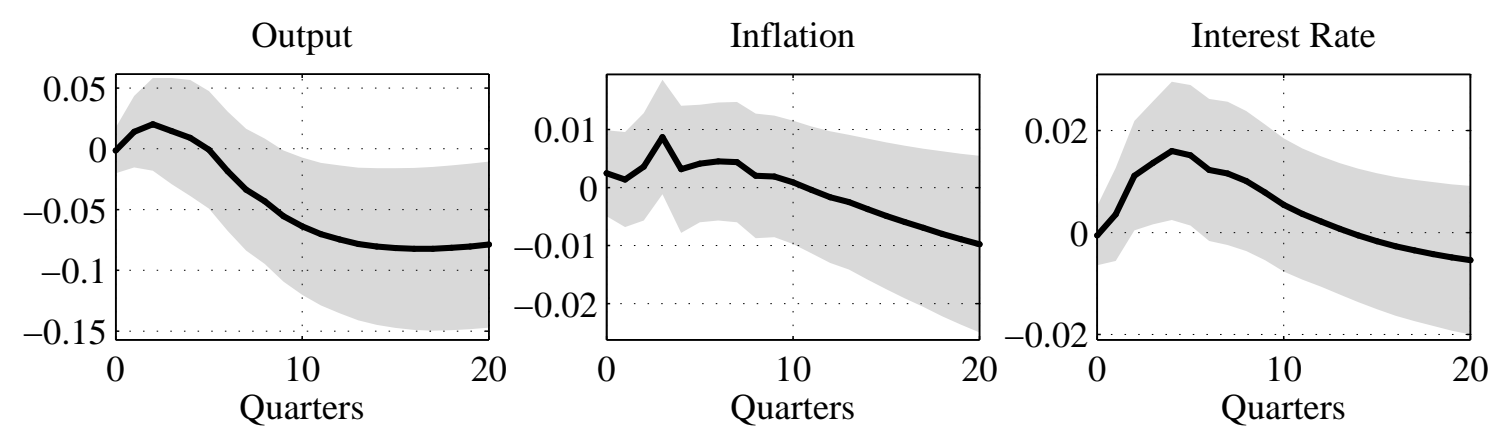

should be no compelling reasons to interpret these estimated responses as the aggregate outcomes of a disinflation policy, as argued by Edelberg et al. (1999) in the context of large fiscal shocks. Accordingly, to assess the robustness of our finding to the selected date, we perform the following three experiments:

- Experiment I: We lead and lag by one quarter all the dates.

- Experiment II: Same as experiment I, but with four lags and leads in all the dates.

The results associated to each experiment for output, inflation, and the nominal interest rate are reported in Figures 5 and 6. Let us first consider the case of a small perturbation (a one quarter lead or lag) in the selected date. Panels (a) and (b) of Figure 5 show that such a small perturbation in the date does not modify our previous findings: output persistently decreases, the response of inflation is positive and becomes negative after about 4 quarters, and the nominal interest rate displays a sizeable and positive hump profile in the short-run. The results are very different if we modify the episode dates in a more important way. Figure 6 reports the responses for a four-quarter lag or lead in all the episodes dates (Experiment II). Panel (a) of Figure 6 displays the response when the episodes dates are lagged by four quarters. In this case, the response of output becomes persistently positive and we get positive responses of inflation and the nominal interest rate. The identified shock is broadly similar to a positive demand shock which increases output, inflation, and the nominal interest rate. Panel (b) of Figure 6 displays the response when the dates are shifted by a four-quarter lead. Now, both output and inflation respond negatively to the identified shock. This shock can be interpreted as a negative demand shock that simultaneously shifts quantities and prices. 
Figure 5: Robustness to episodes (Experiment I)

(a) 1-quarter lag
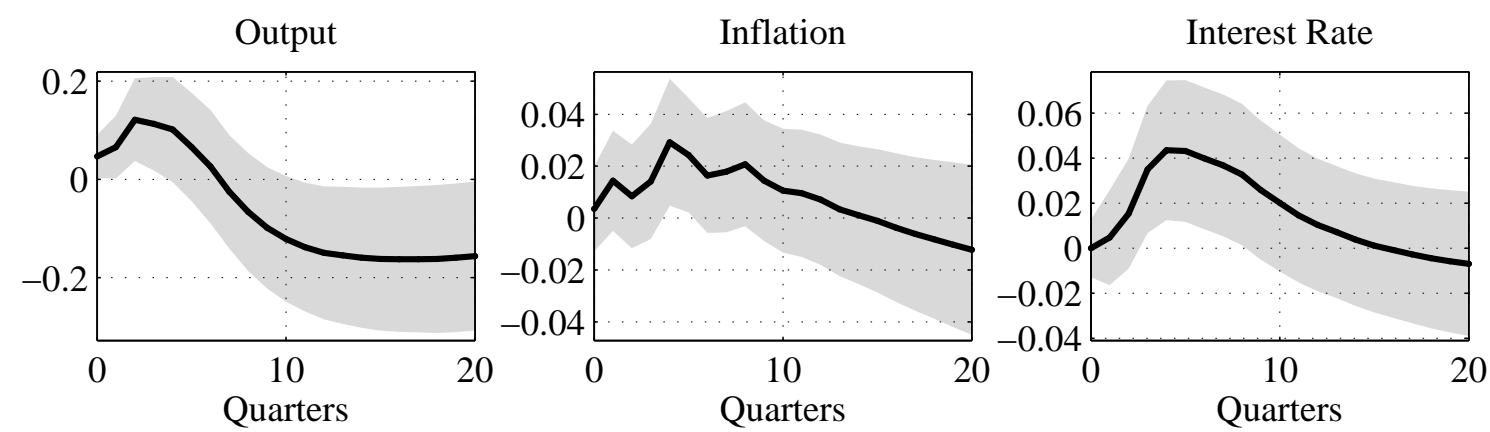

(b) 1-quarter lead
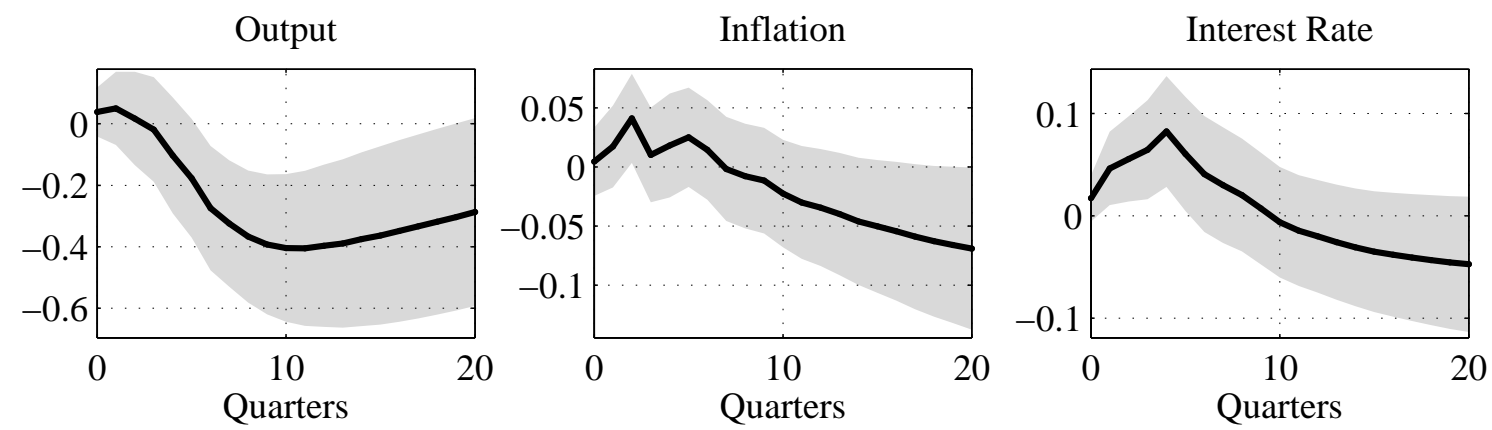

Figure 6: Robustness to episodes (Experiment II)

(a) 4-quarter lag
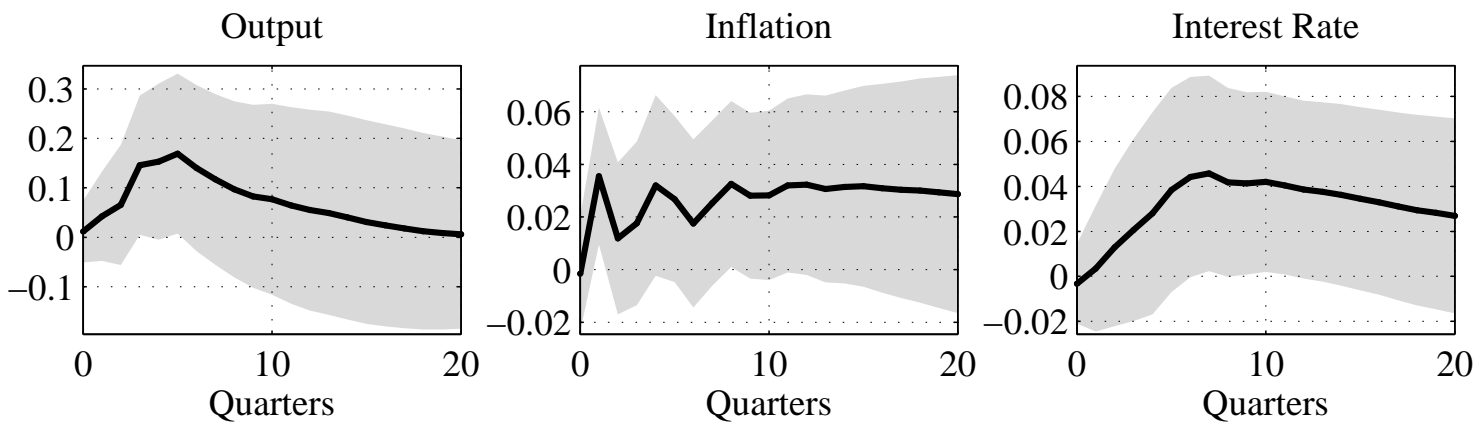

(b) 4-quarter lead
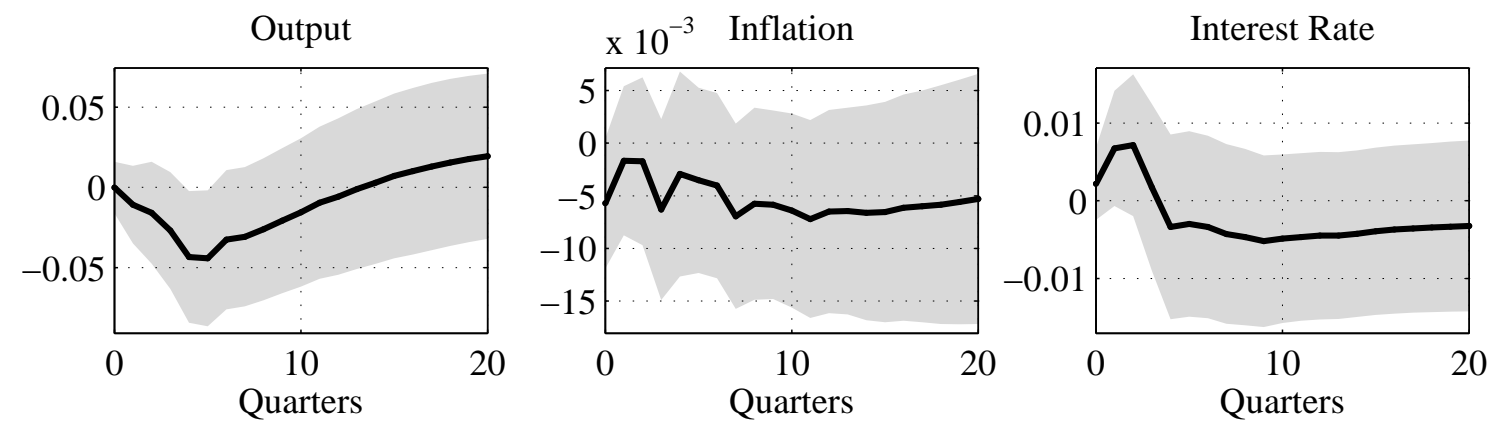


\subsection{Robustness to the VAR Specification}

An additional way to check the robustness of our results is to investigate the sensitivity of the estimated response to alternative specifications of $Z_{t}$. We go back to the model with our eight episodes and examine the role played by the long-run relationship imposed on nominal variables, the addition of new variables, as well as alternative definitions of inflation.

Let us first consider the consequences of our assumed long-run restrictions. Indeed, our specification of $Z_{t}$ in equation (4) imposes that the nominal variables -inflation, wage inflation, the nominal interest rate, and money growth - reach the same level in the longrun. We now investigate the role played by this restriction on the short-run dynamics of output, inflation, and the nominal interest rate. In this experiment, the vector $Z_{t}$ does not impose this restriction and accordingly rewrites:

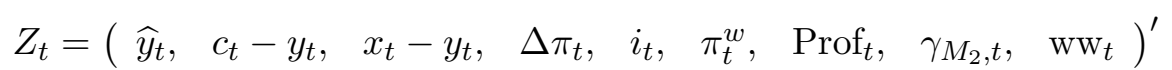

With this new vector $Z_{t}$, we re-estimate the model using the identification strategy of Section 2.1. Panel (a) of Figure 7 reports the estimated responses of output, inflation, and the nominal interest rate. The comparison of Figures 2 and 7 shows that relaxing the long-run restrictions imposed on nominal variables is of no substantial consequence on our previous findings.

We now investigate the effect of the addition of new variables in $Z_{t}$. We first inspect the consequences of introducing the Commodity Research Bureau (CRB) price index of raw materials (see Leeper and Roush (2003)). Indeed, our results suggest a short-run and persistent increase in prices which seems reminiscent of the so-called price puzzle often arising in monetary SVAR models (see Christiano et al. (1999) for a survey) in the face of stationary shocks. Indeed, on several occasions in our sample, a rise in inflation has followed a rise in the Federal funds rate and in commodity prices. Thus, omitting a commodity price from $Z_{t}$ could potentially lead to the apparently paradoxical result that an intended monetary tightening leads to an increase in inflation. Adding the CRB price index of raw materials has however little effect on our conclusions, as can be seen in panel (b) of Figure 7. Indeed, while this commodity price is sufficient to mitigate the price puzzle arising in a monetary SVAR model perturbed by stationary monetary policy shocks, it does not alter the inflation profile obtained in our empirical results. This suggests that these inflation dynamics are a key feature of a disinflation policy.

Similarly, some of the monetary episodes we consider are almost contemporaneous to oil price shocks. Thus, one may wonder whether the persistent decline in output following the 
identified disinflation policy might rather reflect the impact of a large increase in oil prices at the end of the seventies. ${ }^{12}$ To control for this possibility, we consider two alternative measures of oil shocks. First, we simply settle for adding in $Z_{t}$ the growth rate of the West Texas Intermediate Crude Spot Price and we re-estimate the model. As shown in Panel (c) of Figure 7 the shape of the responses are left unaffected by this modification of $Z_{t}$. Second, we build a second set of dummies corresponding to the oil shocks episodes considered by Hamilton (2003). These episodes are meant to capture large exogenous disruptions in the world petroleum supply. Within our sample, the dates are: 1973:4, 1978:4, 1980:4, and 1990:3. These dummies are scaled according to the drop in world production, as reported by Hamilton (2003). Panel (d) of Figure 7 reports the responses when controlling for these dates. As is clear, including these large oil shocks has little effect on our results. In particular, inflation dynamics are virtually unchanged.

In our evaluation of disinflation policies, we used the growth rate of the GDP deflator as a measure of inflation. However, central banks often focus on alternative measures of inflation, such as the growth rate of the consumer price index (CPI). We now check the robustness of our results to such alternative measures of inflation. Panels (e) and (f) of Figure 7 report the responses when the CPI price index including or excluding food and energy expenditures is used instead of the GDP deflator. In these two cases, the negative response of output and the short-run positive hump-shaped profile of the nominal interest rate are maintained. The short-run response of inflation is a slightly affected since the positive and persistent profile appears somewhat less pronounced. Finally, we investigate the sensitivity of our findings to another measure of the short-run nominal interest rate. We now use the three-month Treasury Bill rate on the secondary market instead of the Federal fund rate. The responses are reported in Panel (g) of Figure 7. The comparison with Figure 2 shows that our benchmark results are unaffected by considering this alternative measure of the nominal interest rate.

\subsection{An Alternative Identification Strategy}

Our evaluation of disinflation policy is conducted using normalized episodes of hypothetical disinflation policies. A simple way to evaluate the robustness of our findings is to compare the estimated responses using scaled dummies to what one would obtain from alternative identification strategies. The long-run identification restriction à la Blanchard and Quah

\footnotetext{
${ }^{12}$ Hoover and Perez (1994) argue that it is not possible to distinguish monetary shocks as identified with the narrative approach from an oil shock as a cause of a recession. This is especially true when variables are taken in isolation and when the effects of monetary policy are obtained from single equation restrictions. Our approach combines a large set of variables from which it is possible to properly identify the effects of monetary policy.
} 
Figure 7: Robustness to Specification

(a) No long-run restriction

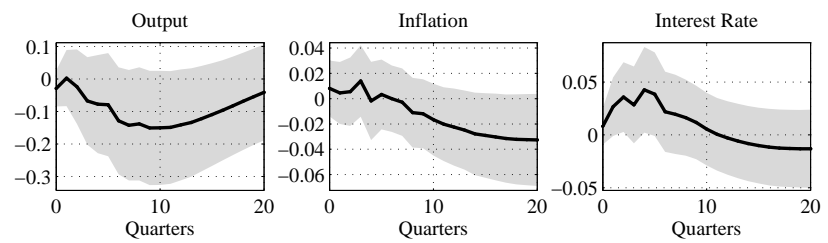

(b) CRB index (raw materials)
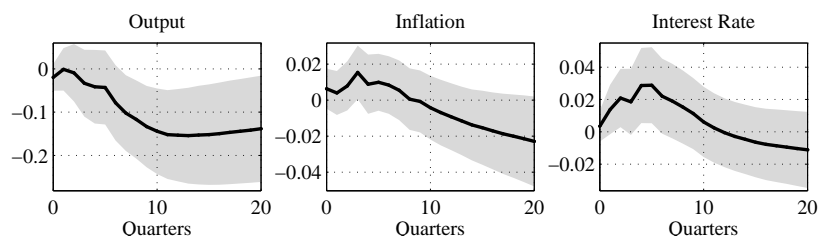

(c) Oil Price
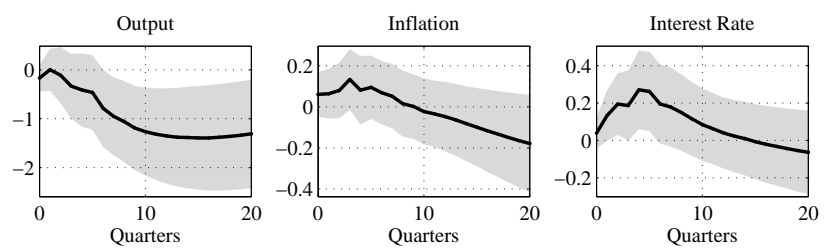

(d) Hamilton Dates
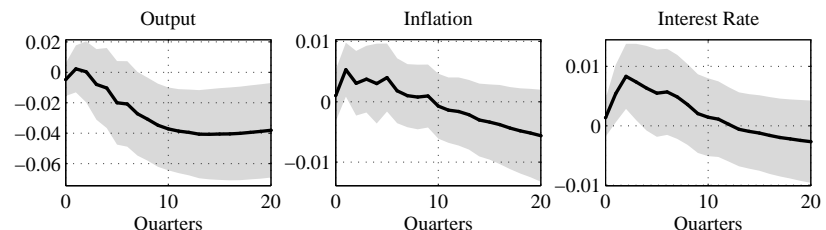

(e) CPI
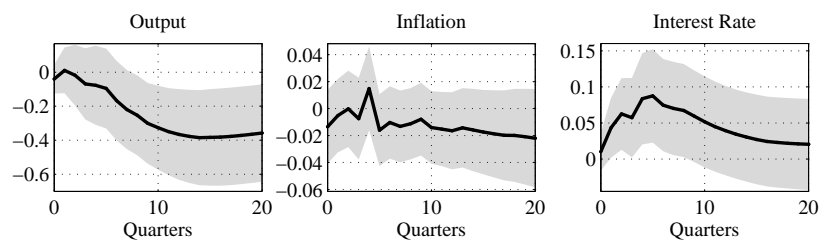

(f) CPI less food and energy
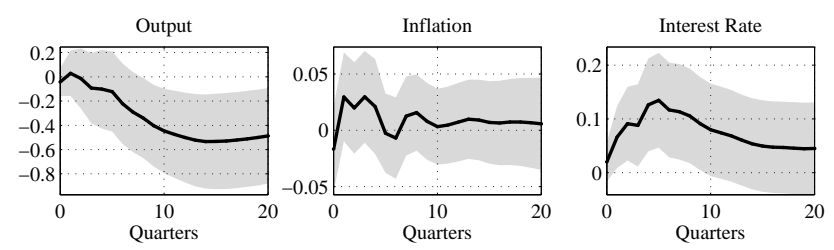

(g) Treasury Bill rate

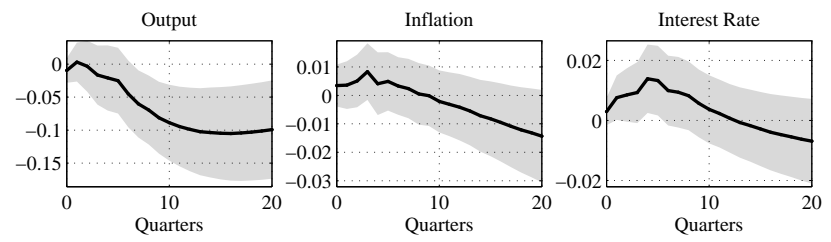


(1989) offers another attractive way to assess the effects of a permanent disinflation policy. This identification strategy departs from that with scaled dummies in that it generates an episode for all the sample points. ${ }^{13}$ We now assume that the stochastic process for $Z_{t}$ is of the form

$$
Z_{t}=B_{0}+\sum_{j=1}^{p} B_{1, j} Z_{t-j}+v_{t}
$$

where

$$
\mathrm{E}\left(v_{t}\right)=0 ; \mathrm{E}\left(v_{t} v_{t-s}^{\prime}\right)=\left\{\begin{array}{l}
0, \forall s \neq 0 \\
\Omega, \text { for } s=0
\end{array}\right.
$$

The specification of $Z_{t}$ is the same as in equation (4). In particular we assume the same long-run restrictions among nominal variables. In addition, in the spirit of Blanchard and Quah (1989), we use the identifying restriction that only disinflation shocks can have a long-run effect on inflation in $Z_{t} \cdot{ }^{14}$ Using this restriction, we can generate the responses of the components of $Z_{t}$ to this policy shock. The results are reported in Figure 8. The

Figure 8: Response to disinflation episodes (Blanchard and Quah identification)
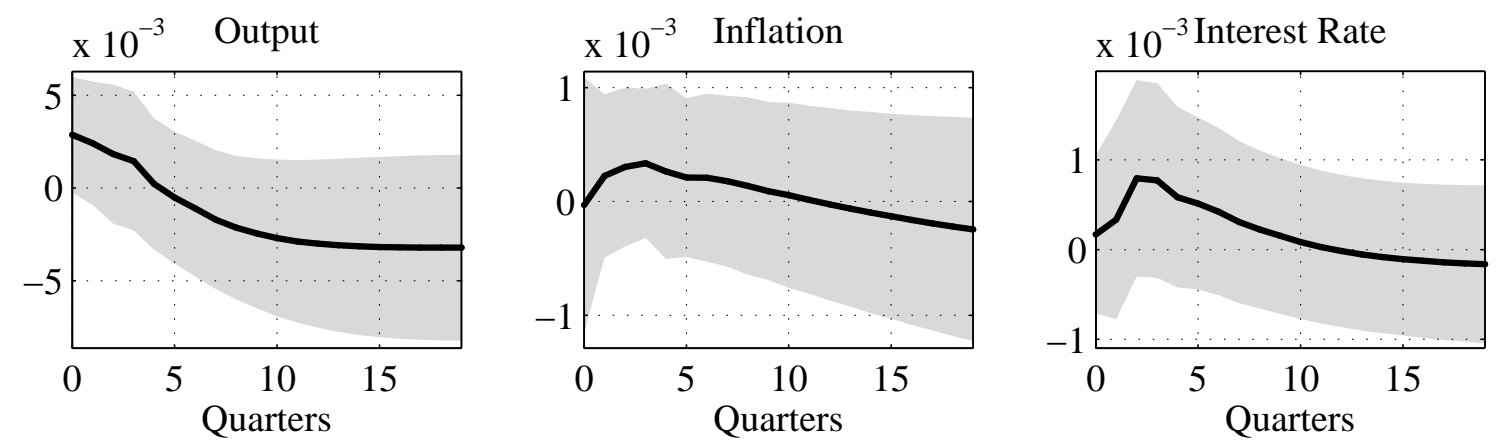

responses of output, inflation, and the nominal interest rate are similar to those obtained using selected episodes both in sign and persistence. ${ }^{15}$ The main difference is found in the very short-run responses of output and other real variables, since they display a small positive - although not significant - response to the permanent disinflation shock. In contrast, the responses of inflation and the nominal interest rate are virtually the same. It is worth noting that the response of output is closely related to that obtained in our previous identification strategy when the episode variable is lagged by one quarter (see Panel (a) of Figure 5). This suggests that our selected episodes are leading the policy

\footnotetext{
${ }^{13}$ Cecchetti and Rich (2001) use long-run restrictions on output to assess the sacrifice ratio. However, in our framework, these restrictions are imposed on nominal variables rather than on real variables.

${ }^{14}$ These results are similar if we use other nominal variables (nominal interest rate, wage inflation and money growth) for the identification of the policy shock with long-run restrictions.

${ }^{15}$ Note that the size of the shocks is different as in this decomposition, shocks occur in each and every period and are therefore way smaller. The responses of all variables in $Z_{t}$ are reported in Figure 18 in Appendix.
} 
shocks as identified with long-run restrictions. This finding is confirmed by Granger causality tests. Using two or four lags for the scaled dummies associated to our eight selected episodes, the exclusion test leads us to reject the null hypothesis that the dates of disinflation policy episodes do not Granger-cause the disinflation shocks. This finding echoes previous statements by Romer and Romer (1989), since episodes isolated with their narrative approach may represent intentions rather than actions of the Federal Reserve. ${ }^{16}$

Finally, one can always argue that the so identified disinflation shock may actually reveal negative technology shocks and that estimated responses ought to be highly contaminated by this type of shocks. ${ }^{17}$ However, two elements mainly differentiate our estimated disinflation shock from a standard technology shock. First of all, the estimated responses with a dummy variable and a SVAR model with a long-run restriction deliver the same long-run effect of disinflation policy: this policy reduces inflation and the Fed fund permanently in the long-run. On the contrary, when we identify a permanent technology shock using the long-run restriction strategy used by Blanchard and Quah (1989) or Galí (1999), we find that the response of inflation to a negative technology shock remains always positive at all horizons. In addition, the response of inflation is twice as large as that obtained with our identified monetary policy shock.

\section{A Model of Disinflation}

The model is a standard new Keynesian model. The economy is populated by a large number of identical infinitely-lived households and firms. Each firm produces a single good which can be used for consumption and investment purposes. The firm has monopoly power over for the good it produces. Each good is produced with capital and labor. The production of the final good also requires intermediate material goods. The model features all standard real frictions that are commonly introduced in the literature (habit persistence, adjustment costs, utilization). We only depart from the standard model in that we follow Ravn et al. (2006) and assume that habit persistence affects each good individually rather than the consumption bundle as a whole. This plays a key role for the results. Our benchmark model features both deep habits and price stickiness. For comparison purposes we will also consider a version of the standard habit model with price stickiness and a version that will also feature sticky wages. ${ }^{18}$

\footnotetext{
${ }^{16}$ Note that the reverse is not true. Causality from the policy shocks identified in the SVAR to the episodes variable is strongly rejected by the data.

${ }^{17}$ Oil price shock is another good candidate (see Hoover and Perez (1994)), but we have already shown that our results are robust to this variable.

${ }^{18}$ The interested reader is referred to Erceg, Henderson and Levin (2000) or Christiano et al. (2005) for a formal description of nominal wage contracting problem.
} 


\subsection{The Household}

Household preferences are characterized by the lifetime utility function:

$$
\sum_{\tau=0}^{\infty} \beta^{\tau}\left[\log \left(s_{t+\tau}\right)+\frac{\nu^{m}}{1-\sigma_{m}}\left(\frac{M_{t+\tau}}{P_{t+\tau}}\right)^{1-\sigma_{m}}-\frac{\nu^{h}}{1+\sigma_{h}} h_{t+\tau}^{1+\sigma_{h}}\right]
$$

where $0<\beta<1$ is a constant discount factor, $M / P$ is real balances and $h$ is hours worked supplied by the representative household. The household also derives utility from the consumption index $s_{t}$. We follow Ravn et al. (2006) and assume that $s_{t}$ captures the idea that preferences feature habit persistence on each good the household consumes rather than on the consumption bundle as a whole. Following these authors we refer to this phenomenon as "deep habits". The consumption index, $s_{t}$, then takes the form

$$
s_{t}=\left(\int_{0}^{1}\left(c_{t}(j)-b \bar{c}_{t-1}(j)\right)^{\theta} \mathrm{d} j\right)^{\frac{1}{\theta}}
$$

Following Abel (1990), preferences feature "catching up with the Joneses" as the household values the difference between her current consumption of good $j, c_{t}(j)$, and aggregate past consumption of the same good, $\bar{c}_{t-1}(j)$. Note however that, as in Ravn et al. (2006), this catching up phenomenon takes place for each individual good. The parameter $b$ measures the degree of external habit formation in consumption and is common to all varieties. We will also consider an alternative specification in which preferences feature habit formation with regard to the consumption bundle as a whole rather than each consumption good. In this case, $s_{t}$ writes as $s_{t}=c_{t}-b \bar{c}_{t-1}$. This will be referred to as the "standard habit" specification.

The budget constraint is standardly given by

$$
\begin{aligned}
B_{t} Q_{t}+M_{t}+\int_{0}^{1} P_{t}(j)\left(c_{t}(j)+i_{t}(j)+v_{t}(j)\right) \mathrm{d} j= & B_{t-1}+M_{t-1}+\Omega_{t} \\
& +P_{t} r_{k, t} u_{t} k_{t}+P_{t} w_{t} h_{t}+\Pi_{t}
\end{aligned}
$$

where $w_{t}$ is the real wage; $P_{t}$ is the nominal price of the domestic final good; $c_{t}(j)$ is consumption of good $j$ and $i_{t}(j)$ is investment expenditure in variety $j$. These investment goods are then combined according to the following CES aggregator

$$
i_{t}=\left(\int_{0}^{1} i_{t}(j)^{\theta} \mathrm{d} j\right)^{\frac{1}{\theta}}
$$

to accumulate capital according to the law of motion

$$
k_{t+1}=(1-\delta) k_{t}+i_{t}-\omega \Phi_{i}\left(\frac{i_{t}}{i_{t-1}}\right) i_{t}-(1-\omega) \Phi_{k}\left(\frac{i_{t}}{k_{t}}\right) k_{t}
$$


where $\delta \in(0,1)$ is the constant depreciation rate. $\omega$ is a binary parameter that enables us to select among the two adjustment costs specifications we consider. Setting $\omega=1$ we select a dynamic investment adjustment cost specification (see Christiano et al. (2005), Christiano and Fisher (2003) and Eichenbaum and Fisher (2005)). In this environment, it is the growth rate of investment which is penalized when varied in the neighborhood of its steady state value. The function $\Phi_{i}(\cdot)$ reflects the presence of investment adjustment costs. We assume that $\Phi_{i}(\cdot)$ satisfies (i) $\Phi_{i}(1)=\Phi_{i}^{\prime}(1)=0$ and (ii) $\varphi_{i}=\Phi_{i}^{\prime \prime}(1)>0$. It follows that the steady state of the model does not depend on the parameter $\varphi_{i}$ while its dynamic properties do. Setting $\omega=0$ we select a capital adjustment costs specification à la Lucas and Prescott (1971), as represented by the function $\Phi_{k}(\cdot)$, that penalizes the investment-to-capital ratio. We then assume that $\Phi_{k}(\cdot)$ satisfies $(i) \Phi_{k}(\delta)=0, \Phi_{k}^{\prime}(\delta)=1$ and (ii) $\varphi_{k}=\delta \Phi_{k}^{\prime \prime}(\delta)>0$. Just like investment adjustment costs, the steady state of the model does not depend on the parameter $\varphi_{k}$ while its dynamic properties do. The dynamic specification for adjustment costs is a significant source of internal propagation mechanisms as the impulse response analysis will show. $k_{t}$ is the amount of physical capital owned by the household and rented to the firms at the real rate $r_{k, t}$. Only a fraction $u_{t}$ of the capital stock is utilized in any period. Utilization of the capital stock triggers expenditures in the form of each good $j$ such that

$$
z\left(u_{t}\right) k_{t}=\left(\int_{0}^{1} v_{t}(j)^{\theta} \mathrm{d} j\right)^{\frac{1}{\theta}}
$$

where $z(\cdot)$ is a strictly increasing convex function, which satisfies (i) $z(1)=0, z^{\prime}(1)>0$ and (ii) $\sigma_{z}=z^{\prime \prime}(1) / z^{\prime}(1)>0 . M_{t-1}$ is the amount of money that the household brings into period $t$, and $M_{t}$ is the end of period $t$ money holdings. $\Omega_{t}$ is a nominal lump-sum transfer received from the monetary authority and $\Pi_{t}$ denotes profits the household receives from the firms. $B_{t}$ is the amount of nominal claims the household buys at price $Q_{t}$ to transfer wealth across periods.

The household then determines her consumption, savings, money holdings and labor supply plans by maximizing (5) subject to (6)-(10). An interesting feature of this approach is that the total demand of good $j$ for consumption purpose features a dynamic component

$$
c_{t}(j)=\left(\frac{P_{t}(j)}{P_{t}}\right)^{\frac{1}{\theta-1}} s_{t}+b c_{t-1}(j)
$$

Note that in the case of standard habit formation the demand function reduces to the standard static form

$$
c_{t}(j)=\left(\frac{P_{t}(j)}{P_{t}}\right)^{\frac{1}{\theta-1}} c_{t} .
$$


The other components of demand, $d_{t}(j) \in\left\{i_{t}(j), v_{t}(j)\right\}$, are standardly given by

$$
d_{t}(j)=\left(\frac{P_{t}(j)}{P_{t}}\right)^{\frac{1}{\theta-1}} d_{t}
$$

\subsection{Producers}

Each good $j$ is produced by means of capital and labor according to a constant returnsto-scale technology, represented by the Cobb-Douglas production function

$$
Y_{t}(j)=\min \left\{\frac{A\left(u_{t}(j) k_{t}(j)\right)^{\alpha} h_{t}(j)^{1-\alpha}-\mathscr{F}}{1-s_{x}}, \frac{x_{t}(j)}{s_{x}}\right\}
$$

where $\alpha \in(0,1) . k_{t}(j), h_{t}(j)$ and $x_{t}(j)$ respectively denote the physical capital, utilized at rate $u_{t}(j)$, the labor input used by firm $j$ and a bundle of material goods used in the production process. $A$ is a positive constant that determines the total factor productivity of the technology. $\mathscr{F}$ denotes the positive fixed cost of production. Material goods are introduced in the model as a way to improve the ability of the model to generate inflation inertia, ${ }^{19}$ as the real marginal cost is now given by

$$
m c_{t}=\left(1-s_{x}\right) \frac{r_{k, t}^{\alpha} w_{t}^{1-\alpha}}{A \alpha^{\alpha}(1-\alpha)^{1-\alpha}}+s_{x}
$$

The parameter $s_{x} \in(0,1)$ is the weight placed on material goods in production. Each firm $j$ purchases a bundle of material goods of the form

$$
x_{t}(j)=\left(\int_{0}^{1} x_{t}(i, j)^{\theta} \mathrm{d} i\right)^{\frac{1}{\theta}}
$$

which yields the demand function

$$
x_{t}(i, j)=\left(\frac{P_{t}(i)}{P_{t}}\right)^{\frac{1}{\theta-1}} x_{t}(j)
$$

Hence the total demand for the material good $j$ addressed to the firm is given by

$$
x_{t}^{d}(j)=\int_{0}^{1} x_{t}(j, i) \mathrm{d} i=\left(\frac{P_{t}(j)}{P_{t}}\right)^{\frac{1}{\theta-1}} x_{t}
$$

where $x_{t}$ is aggregate demand for material goods.

Each firm $j$ operates under perfect competition in the inputs markets, but acts as a monopolistic competitor on the good market. We assume that it is costly for the firm to adjust prices, $P_{t}(j)$, relative to the reference path determined by $\widetilde{\pi}_{t} P_{t-i}(j)$. We follow

\footnotetext{
${ }^{19}$ This assumption will help all the versions of the model we consider, including competing models.
} 
Christiano et al. (2005) and assume $\widetilde{\pi}_{t}=\pi_{t-1}$. Adjusting the price level entails a quadratic cost

$$
\psi_{t}(j)=\frac{\psi}{2}\left(\frac{P_{t}(j)-\widetilde{\pi}_{t} P_{t-1}(j)}{\widetilde{\pi}_{t} P_{t-1}(j)}\right)^{2} y_{t}
$$

This cost is assumed to be proportional to value added, $y_{t}$, and is measured in terms of the basket of intermediate goods, such that

$$
\psi_{t}(j)=\left(\int_{0}^{1} \psi_{t}(i, j)^{\theta} \mathrm{d} i\right)^{\frac{1}{\theta}}
$$

Note that, when inserted into a standard framework, this specification yields a similar log-linear version of Phillips curve as that obtained in a Calvo setting. Hence, the price adjustment cost parameter can simply be set so as to match the standard Phillips curve in a standard setting. ${ }^{20}$ Production and price setting plans are then determined by maximizing profits, as given by

$$
\begin{aligned}
\sum_{\tau=0}^{\infty} \rho_{t+\tau}\left[P_{t+\tau}(j)\left(c_{t+\tau}(j)+d_{t+\tau}(j)\right)\right. & -P_{t+\tau} w_{t+\tau} h_{t+\tau}(j)-P_{t+\tau} r_{k, t+\tau} u_{t+\tau}(j) k_{t+\tau}(j) \ldots \\
& \left.-P_{t+\tau} \frac{\psi}{2}\left(\frac{P_{t+\tau}(j)-\widetilde{\pi}_{t} P_{t+\tau-1}(j)}{\widetilde{\pi}_{t+\tau} P_{t+\tau-1}(j)}\right)^{2} y_{t+\tau}\right]
\end{aligned}
$$

subject to the technological constraint (14), the non consumption demand it faces

$$
d_{t}(j)=\left(\frac{P_{t}(j)}{P_{t}}\right)^{\frac{1}{\theta-1}} d_{t}
$$

where $d_{t}(j)=i_{t}(j)+v_{t}(j)+\psi_{t}(j)+x_{t}^{d}(j)$ (similarly for $d_{t}$ ) and the demand for consumption purposes (equation (11) in the case of deep habits, and equation (12) in the case of standard habit formation).

\subsection{The monetary authorities}

Disinflation episodes are periods of monetary tightening. Such tightening can be achieved in various ways. The central banker can decide to cut money growth, or to rise the nominal interest rate. Hereafter, we will use a nominal interest rule of the form

$$
\log \left(R_{t}\right)=\rho_{r} \log \left(R_{t-1}\right)+\left(1-\rho_{r}\right)\left[\log (\bar{R})+\omega_{y}\left(\log \left(y_{t}\right)-\log (\bar{y})\right)+\omega_{\pi}\left(\log \left(\pi_{t}\right)-\log (\bar{\pi})\right]\right.
$$

where $R_{t}$ is the gross nominal rate of interest. $\bar{y}$ and $\bar{\pi}$ represent, respectively, the level of steady state output and inflation. A disinflation episode will then be modeled as a permanent decrease in $\bar{\pi}$.

\footnotetext{
${ }^{20}$ This will be our calibration strategy.
} 
This modeling strategy is debatable. One may object that a nominal interest rate rule was not explicitly used in the pre-Volcker period. However, as argued by Taylor (1999), nominal interest rate rule are a useful and quite accurate tool to understand various monetary episodes in the post World-War II period. Furthermore, we will assess the robustness of our findings to alternative specifications of disinflation policy. In particular, for comparative purposes, we will also use (i) an active money growth rule in which the central banker has explicit concern about inflation and output gap, and (ii) a discretionary control of money injections.

\section{Results}

This section discusses the ability of the model to account for disinflation episodes. We first report and discuss the parametrization of the model. We then present our results and discuss the role of (i) monetary policy and (ii) real frictions.

\subsection{Calibration}

The economy is calibrated on US data for the post World War II period. We borrow most of our parameters from the literature dealing with new Keynesian models (as exemplified by Christiano et al. (2005)). Our benchmark calibration is reported in Table 1.

The discount factor, $\beta$, is set such that households discount the future at a $3 \%$ annual rate, yielding $\beta=0.9926$. The parameter determining the inverse of the Frishian labor supply elasticity, $\sigma_{h}$, and the markup that applies to wages in the wage contracts version of the model are borrowed from Christiano et al. (2005). This led us to set $\sigma_{h}=1$ and a $5 \%$ markup rate over wages in a version of the model featuring nominal wage contracts. As far as the habit parameter is concerned, we have to consider two alternative values. Most of the literature that has attempted to estimate standard habit specification in a general equilibrium framework (see Beaudry and Guay (1996), Boldrin, Christiano and Fisher (1999), or Christiano et al. (2005) among others) report a value for the habit parameter close to 0.7 . We therefore set $b=0.7$ in the model with the standard habit specification (labeled (S) in Table 1). Ravn et al. (2006) report that the estimation of a model featuring deep habits leads to higher values of the habit parameter (close to 0.9). We therefore set $b=0.88$ in our deep habits version of the model (labeled (D) in the table). Note that when we impose that the habit parameter is set to 0.88 in both specification (standard and deep habits) our results are essentially unaffected.

The share of material goods in value added is set to $50 \%$ according to the study by 
Table 1: Benchmark calibration

\begin{tabular}{|c|c|c|}
\hline Parameter & Mechanism & $\begin{array}{l}\text { Value } \\
\end{array}$ \\
\hline \multicolumn{3}{|c|}{ Preferences } \\
\hline$\beta$ & Discount factor & 0.9926 \\
\hline$\sigma_{h}$ & Inverse of labor supply elasticity & 1.0000 \\
\hline$\mu_{w}$ & Markup rate (wages) & 0.0500 \\
\hline$b$ & Habit parameter & $0.70(\mathrm{~S}), 0.88(\mathrm{D})$ \\
\hline \multicolumn{3}{|c|}{ Technology } \\
\hline$s_{x}$ & Share of material goods & 0.5000 \\
\hline$\alpha$ & Capital elasticity & 0.3600 \\
\hline$\mu$ & Markup rate (goods) & 0.4000 \\
\hline$\sigma_{z}$ & Elasticity of capital utilization cost & 0.0100 \\
\hline \multicolumn{3}{|c|}{ Capital Accumulation } \\
\hline$\delta$ & Depreciation rate & 0.0250 \\
\hline$\varphi_{k}$ & Capital adjustment cost parameter & 4.5000 \\
\hline$\varphi_{i}$ & Investment adjustment cost parameter & 2.5000 \\
\hline \multicolumn{3}{|c|}{ Nominal rigidities } \\
\hline$\xi_{p}$ & Price stickiness & 0.4000 \\
\hline$\xi_{w}$ & Wage stickiness & 0.3333 \\
\hline \multicolumn{3}{|c|}{ Monetary Policy } \\
\hline$\rho$ & Interest rate smoothing & 0.8000 \\
\hline$\omega_{\pi}$ & Weight on inflation & 2.0000 \\
\hline$\omega_{y}$ & Weight on output & 0.0500 \\
\hline
\end{tabular}


Jorgenson, Gollop and Fraumeni (1987). The fixed cost in the production function, $\mathscr{F}$, is set to guarantee that profits are zero in steady state. This assumption is in line with previous studies by Hall (1988), Basu and Fernald (1994) or Rotemberg and Woodford (1999) who argue that that economic profits are close to zero. The parameter $\alpha$ is then set to 0.36 so as to generate a steady state labor share of $64 \%$. There does not exist any firm consensus on the level of markups in the aggregate economy. Estimates of the level of markups vary importantly and go from almost zero to more than $100 \%$ depending on the industry we consider. We follow Morrison (1990) and Rotemberg and Woodford (1995) and set a markup rate of 0.4. Following Christiano et al. (2005), we arbitrarily set the elasticity of the utilization cost function to 0.01 .

The depreciation rate of the economy is set such that capital depreciates at a $10 \%$ annual rate implying $\delta=0.025$. In our benchmark experiment, we mainly consider capital adjustment costs $(\omega=0)$. The parameter, $\varphi_{k}$, is set such that we roughly match the investment/capital ratio elasticity of the capital adjustment costs specification reported in Boldrin et al. (1999). This led us to set $\varphi_{k}=4.5$. As a robustness check we will also set $\omega=1$, therefore considering investment adjustment costs. There does not seem to exist any consensus on the value of the investment adjustment costs parameter. Smets and Wouters (2005) report a value close to 6, while Jaimovich and Rebelo (2006) use a value of 1.3. We use the value estimated by Christiano et al. (2005), $\varphi_{i}=2.5$, which lies in the middle of the range of available estimates. ${ }^{21}$

The values used to set the degree of nominal stickiness are rather standard and are borrowed from Christiano et al. (2005). We assume that, should prices be set according to a Calvo contract scheme, the firms would reset prices once every 2.5 quarters. The degree of wage stickiness in the wage contract version of the standard New Keynesian model is set such that wages are set once every 3 quarters on average. We then use the mapping between the log-linear version of the New Keynesian Phillips curve in the Calvo version and the price adjustment costs version of the model to set the price adjustment costs parameter.

The monetary policy rule is rather standard. We set the interest rate soothing parameter to $\rho=0.8$ indicating that smoothing is quite substantial in the conduct of monetary policy. This value is in line with previous estimates reported in the literature (see Clarida, Galí and Gertler (1999)). We set a low weight on output, $\omega_{y}=0.05$. This is in line with existing estimates of Taylor rules which indicate that monetary authorities place a

\footnotetext{
${ }^{21}$ We performed a sensitivity analysis of the results to changes of this value and found no major consequences as long as we do not let it go to either zero or infinity. This will be discussed further in the next section.
} 
very low weight on output stability in the rule. The weight on inflation, $\omega_{\pi}=2.00$ is slightly larger than the commonly used lower value of 1.5. It is however worth noting that disinflation periods are usually characterized by a more aggressive behavior of the central bankers with regard to inflation. This value of $\omega_{\pi}$ takes that feature into account. Our sensitivity analysis will show the role of this assumption for our results. Finally note that we have not set the parameter ruling the elasticity of money demand in the model. We postpone the discussion of this parameter to the next section, as it does not affect our results in the case of a Taylor rule.

\subsection{Accounting for Disinflation Episodes}

This section investigates the ability of new Keynesian models to account for the empirical facts reported in Section 2. We consider three models: (i) the standard new-Keynesian model with sticky prices and standard catching-up with the Jones, (ii) an extended version of the previous model in which we add nominal wage contracts and (iii) our deep habits version of the new-Keynesian model with sticky prices. We then run the following experiment. We assume that the monetary authorities announce they will now target a new inflation rate that is 1 point below the current level and then analyze the resulting transition dynamics. From a technical point of view, this amounts to analyzing the transition dynamics between two steady states, the first one having a higher inflation rate than the second one. This is in line with the way our empirical strategy was conducted as our dummy variables corresponds to a structural break on average inflation. Figure 9 reports the results in our benchmark calibration. The figure reports four responses: the data (plain line) along with the associated confidence interval (shaded area), the deep habit model, and the two versions of the standard new-Keynesian model.

As can be seen from the figure, the model with deep habits outperforms the other two versions of the new-Keynesian model. More precisely, it is able to match the dynamics of inflation and the nominal interest rate, and is the only one to generate a deep recession for output.

In order to understand the performances of the deep habit model, it is first useful to characterize the sources of the failure of the standard model. Indeed, both standard new Keynesian models fail along all dimensions of the data, despite the presence of many rigidities, either nominal or real. Indeed, as soon as the central banker reduces the targeted level of inflation, current inflation becomes mechanically too high with regard to the new target. Inflation targeting triggers an increase in the nominal interest rate. Provided the Taylor rule is aggressive enough the real interest rate increases. This discourages 
Figure 9: Benchmark Experiment
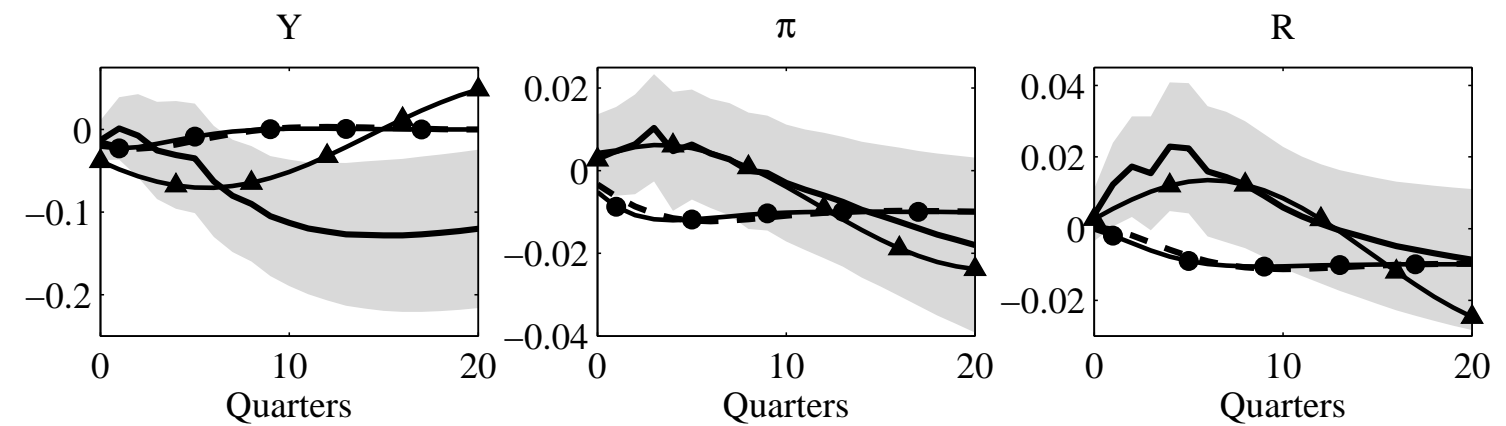

Note: $\longrightarrow$ Data; $\longrightarrow$ Deep Habits and sticky prices; $\rightarrow$ Standard habits and sticky prices; - - Standard habits, sticky prices and sticky wages; Shaded area: $95 \%$ confidence interval.

consumption and investment and creates a recession. The resulting decline in inputs demand drives the marginal cost downward. This is illustrated in Figure 10 that reports the evolution of marginal costs in the models we consider. In the aftermath of this initial

Figure 10: Evolution of the marginal cost

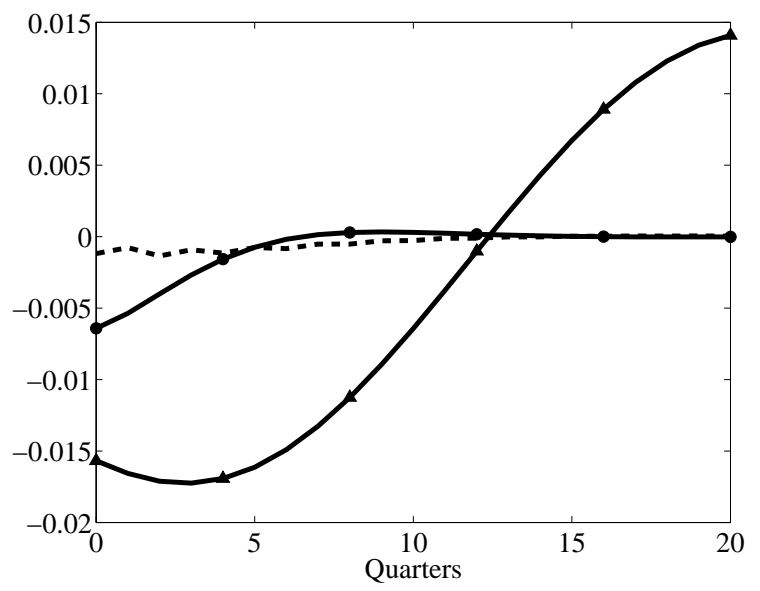

Note: $\multimap$ Deep Habits and sticky prices; —-Standard habits and sticky prices; - - Standard habits, sticky prices and sticky wages; Shaded area: $95 \%$ confidence interval.

decline, the relative decrease in prices drives the demand for good upward so that the phenomenon reverts and the marginal cost steadily goes back to its long-run level. In other words marginal costs always remain below their steady state level. Now, let us recall that the new Phillips curve in this class of model takes the form

$$
\pi_{t}=\kappa m c_{t}+\frac{\gamma}{1+\beta \gamma} \pi_{t-1}+\frac{\beta}{1+\beta \gamma} \pi_{t+1}
$$

where $\kappa$ is a positive constant that depends on other deep parameters (in our setting $\psi, \beta, \gamma)$. It is then clear that the inflation rate is essentially determined by the discounted 
sum of future marginal costs as

$$
\pi_{t}=\gamma \pi_{t-1}+\kappa \sum_{\tau=0}^{\infty} \beta^{\tau} m c_{t+\tau}
$$

Since the marginal costs converge to their steady state level from below so does the inflation rate. This failure also obtains in the nominal wage contract economy as the existence of wage rigidities do not affect the Phillips curve. Consequently, the model cannot reproduce the response of the nominal interest rate as the initial drop in inflation counters the mechanical effect we just described. Therefore the nominal interest rate does not shift upward on impact. Likewise, since inflation decreases, the decline in output is very limited and the model cannot generate a deep recession.

On the contrary, the deep habit assumption enhances the ability of the model to account for the observed pattern of the data. As indicated in Figure 9, the model can account for the initial positive hump in the inflation rate and the nominal interest rate, and can generate a recession in output. ${ }^{22}$ As before, the decrease in the target triggers a mechanical decrease in demand in the model, provided the Taylor rule is aggressive enough with regard to the inflation gap. As explained by Ravn et al. (2006), this decrease in aggregate demand triggers a decrease in the price elasticity of the consumption demand of each good $j$. Indeed, this demand function is composed of two terms. The first term, $\left(\frac{P_{t}(j)}{P_{t}}\right)^{\frac{1}{\theta-1}} s_{t}$, is price elastic with an elasticity of $1 /(1-\theta)$. The second term, $b c_{t-1}(j)$, originates from the habitual consumption of good $j$ and is perfectly price inelastic. The price elasticity of the consumption demand for good $j$ is a weighted average of the elasticities of these two terms. The weight on the non zero elasticity is an increasing function of current consumption growth. Hence, the larger the demand for good $j$, the larger the price elasticity of the consumption part of demand. This component is solely due to the existence of deep habits. The contribution of the price elastic component of the consumption demand for good $j$ decreases in the aftermath of the decline in the inflation target because it leads agents to postpone consumption of each good (and therefore aggregate consumption). Therefore, households are less sensitive to changes in prices. It is then optimal for the firm to limit profit losses - relative to a situation where the aforementioned mechanism does not playthe recession generates by increasing its prices (see Figure 11). ${ }^{23}$ Therefore the deep habit assumption generates an increase in prices during the recession. In the longer run - as the recession dampens - the price elastic component of consumption demand regains its importance, so that price increases no longer help to mitigate profit losses. Therefore,

\footnotetext{
${ }^{22}$ We however want to acknowledge that the recession the model generates is neither deep nor persistence enough with regard to the data. It is however worth noting that, as shown in figure 12, the introduction of working capital further solves the problem.

${ }^{23}$ Note that the deep habit model outperforms the other two versions of the new Keynesian model in terms of profit dynamics.
} 
Figure 11: Evolution of profits

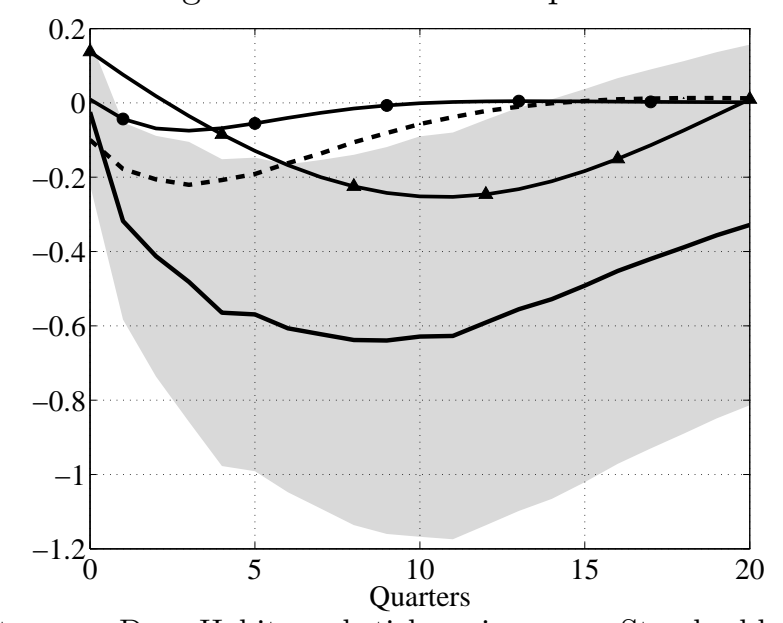

Note: $\multimap$ Deep Habits and sticky prices; — Standard habits and sticky prices; - - Standard habits, sticky prices and sticky wages; Shaded area: 95\% confidence interval.

firms have to cut prices to avoid a persistent loss in demand. Hence, inflation drops. It should be clear that the more persistent the recession, the larger and more persistent the increase in prices because firms can take advantage of the lower demand elasticity for a longer period of time. This point will be further discussed in our robustness analysis. As our specification allows for an initial persistent hump in the inflation rate, the model is able to generate the observed pattern of the nominal interest rate. Since the increase in the inflation rate reinforces the mechanical increase in the inflation gap, the central bank further raises the nominal interest rate which then displays a persistent hump similar to that observed in the data. It is worth noting that both the response of the inflation rate and the nominal interest rate lie within the confidence interval of the response obtained in the data. The model also generates a prolonged and deep recession compared to the earlier specifications of the model. Again, this recession is related to the evolution of prices. The increase in prices not only discourages consumption but also investment and utilization expenditures. Therefore, aggregate demand initially decreases. It shall be noticed that the response of output lies within the empirical confidence interval until period 12. The model then fails to account for the observed dynamics after that period. This failure of the model originates in the fact that the recession is essentially demand driven and created by the increase in prices. As soon as prices diminish, the recession reverts. It should however be acknowledged that the model outperforms the other two specification we consider.

One may however be worried that our model does not feature working capital, which has been shown by Christiano et al. (2005) to be an important transmission channel of transitory monetary policy shocks. In Figure 12, we report the response of output, inflation 
and the nominal interest rate to a disinflation policy shock in a version of the model featuring working capital. ${ }^{24}$ As can be seen from the figure, the working capital assumption

Figure 12: Working Capital
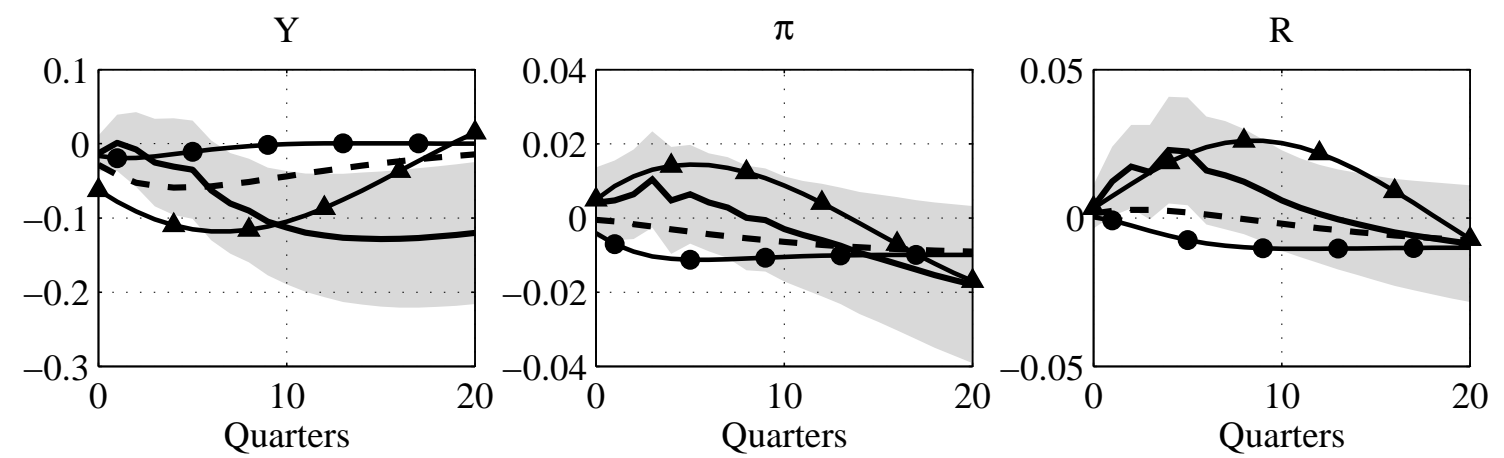

Note: — Data; —-Deep Habits and sticky prices; $\longrightarrow$ Standard habits and sticky prices; - - Standard habits, sticky prices and sticky wages; Shaded area: $95 \%$ confidence interval.

does not affect the main result. The standard sticky price model fails to account for the dynamics of aggregates in the aftermaths of the announcement of a disinflation. It should however be noted that, compared to the previous version, the sticky prices-sticky wages version of the model performs a little bit better than the nominal interest rate first responds positively - though by a very small amount. The disinflationary boom puzzle is gone as the marginal cost includes the interest rate. Indeed, in this case, a disinflation is accompanied by a high interest rate then marginal cost can be high without the implication that output is high. When the monetary policy is made very aggressive $\left(\omega_{\pi} \geqslant 8\right)$ the sticky prices-sticky wages version of the model can mimic the response of the interest rate. Nevertheless inflation never exhibits the hump shaped pattern we found in the data. Hence, while the working capital assumption magnifies the propagation of transitory monetary policy shocks, it does not help explaining the effects of disinflation policy shocks in a standard habit formation framework, while it magnifies the impact of deep habits. In that latter case, the disinflation recession is deeper and exhibits more persistence.

\footnotetext{
${ }^{24}$ In this case, we use the same specification as in Christiano et al. (2005). The utility function writes

$$
\sum_{\tau=0}^{\infty} \beta^{\tau}\left[\log \left(s_{t+\tau}\right)+\frac{\nu^{q}}{1-\sigma_{q}}\left(\frac{M_{t+\tau}^{c}}{P_{t+\tau}}\right)^{1-\sigma_{q}}-\frac{\nu^{h}}{1+\sigma_{h}} h_{t+\tau}^{1+\sigma_{h}}\right]
$$
}

where $M_{t}^{c}$ denotes cash balances. The budget constraint is given by

$B_{t} Q_{t}+M_{t}+\int_{0}^{1} P_{t}(j)\left(c_{t}(j)+i_{t}(j)+v_{t}(j)\right) \mathrm{d} j=B_{t-1}+R_{t}\left(M_{t-1}+\Omega_{t}-M_{t}^{c}\right)+M_{t}^{c}+P_{t} r_{k, t} u_{t} k_{t}+P_{t} w_{t} h_{t}+\Pi_{t}$

Workers must be paid in advance of production such that the firms have to borrow the wage bill from the the financial intermediary at the gross interest rate $R_{t}$. The market clearing condition is then given by $P_{t} w_{t} h_{t}=M_{t}-M_{t}^{c}$. In that case, we follow Christiano et al. (2005) and set $\sigma_{q}=10.65$ and $M^{c} / M=0.44$. 


\subsection{Robustness analysis}

As the preceding analysis made clear deep habits are key to match the response of output, inflation and nominal interest rate during disinflation episodes. It is however important to stress that this assumption per se is not sufficient for the result. We now review the role of the different assumptions placed in the model to get the result.

Monetary Policy: The form of monetary policy plays a role in the result. Figure 13 reports the response of output, the inflation rate and the nominal interest rate in the aftermath of a change in the inflation target. Panel (a) of the figure investigates the case where the central bank is less aggressive with respect to inflation

$\log \left(R_{t}\right)=0.8 \log \left(R_{t-1}\right)+(1-0.8)\left[\log (\bar{R})+0.15\left(\log \left(y_{t}\right)-\log (\bar{y})\right)+1.5\left(\log \left(\pi_{t}\right)-\log (\bar{\pi})\right]\right.$

As far as the standard new Keynesian models are concerned, the results remain the same. ${ }^{25}$ As can be seen from the figure, the deep-habit model no longer produces the hump either in inflation or in the nominal interest rate, and accordingly fails to generate a recession. This result stems from the fact that a low degree of aggressiveness with regard to inflation does not generate a sufficient increase in the inflation rate to generate a deep recession as witnessed by the weak response of output. Therefore, the initial mechanism that drives the marginal costs and the price elasticity of demand downward is broken and the model therefore fails to account for the facts. Panel (b) reports the response of aggregates when the central bank only fights inflation and does not attempt to track the output gap $\left(\omega_{y}=0\right)$. Overall the performance of the model are not altered by this assumption, which comes as no surprise as the main concern of the central bank is inflation stabilization which is especially relevant in periods of disinflation. It is however worth noting that in this case the initial response of output is too large, as the initial increase in the nominal interest rate is not constrained by the willingness of the central bank to limit fluctuations in the output gap. Panel (c) assesses the role of output gap stabilization in the monetary policy, by raising $\omega_{y}$ to 0.5 . As soon as monetary policy puts too much weight on the output gap, the initial increase in the nominal interest rate - and therefore the real interest rate - is limited by the willingness of the central bank to smooth the output gap. Therefore, the model cannot generate any recession and fails to account for the positive hump shaped dynamics of the inflation rate and the nominal interest rate. This result is in line with the definition of Romer and Romer's episodes as these are phases during which the monetary authorities are ready to tolerate output losses to fight inflation.

\footnotetext{
${ }^{25}$ This will be the case for all variations we will consider. We will therefore focus our discussion of the results on the "deep habit case" in the sequel.
} 
Figure 13: Robustness Analysis: Monetary Policy

(a) Standard Taylor rule $\left(\rho=0.8, \omega_{\pi}=1.5, \omega_{y}=0.15\right)$
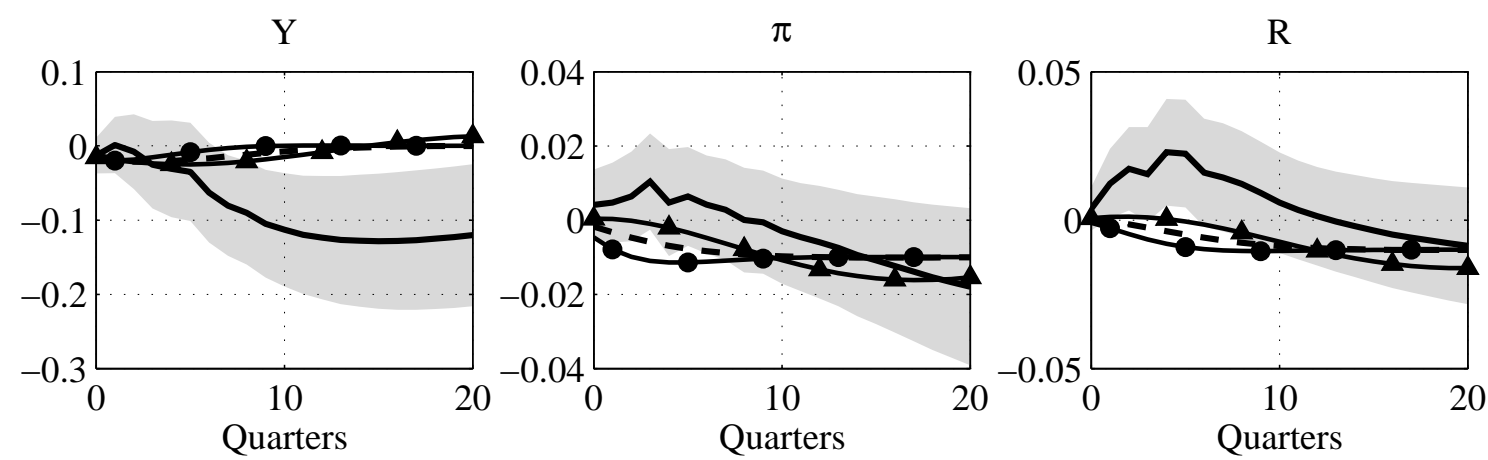

(b) Pure inflation targeting $\left(\rho=0.8, \omega_{\pi}=2, \omega_{y}=0\right)$
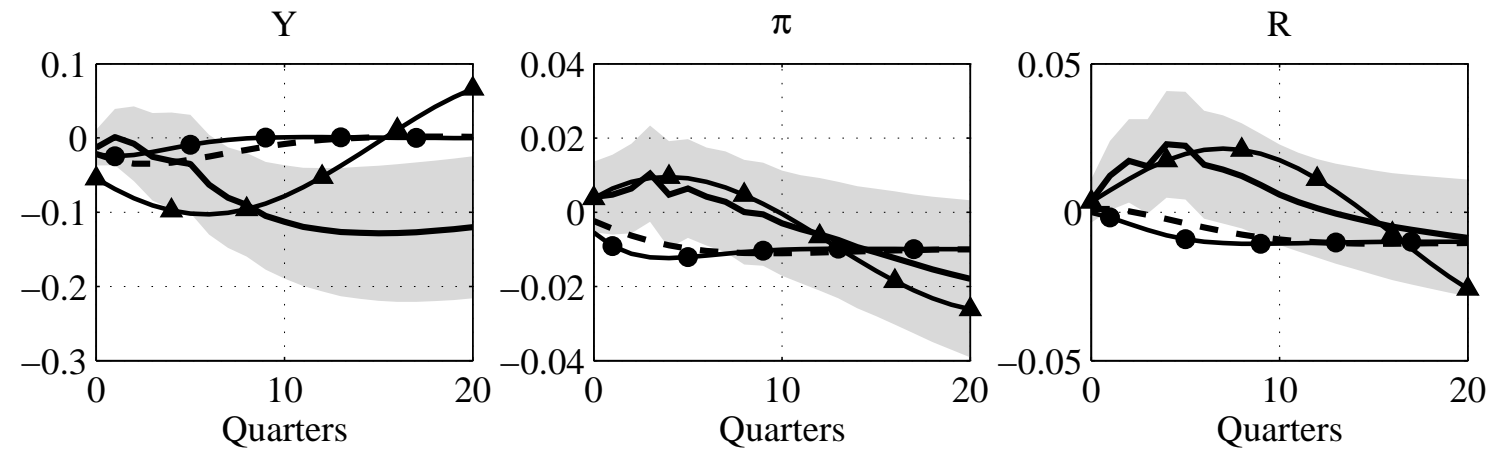

(c) High weight on output gap $\left(\rho=0.8, \omega_{\pi}=2, \omega_{y}=0.5\right)$
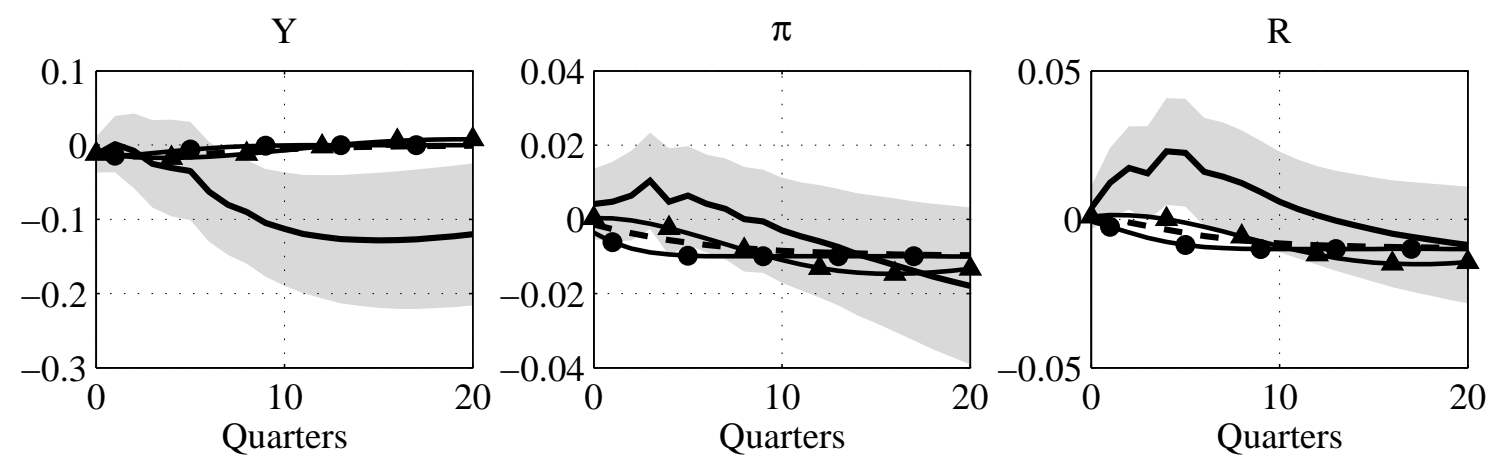

Note: — Data; $\longrightarrow$ Deep Habits and sticky prices; —-Standard habits and sticky prices; - - Standard habits, sticky prices and sticky wages; Shaded area: $95 \%$ confidence interval. 
In order to assess the robustness of our results to alternative representation of disinflation policy, Figure 14 reports the response of aggregates in the case where the central bank does not rely on an interest rate rule to create the disinflation episode but instead cuts money supply growth permanently. The money growth process is calibrated so as to roughly match the dynamics of money supply growth reported in Figure 2. This led us to assume that the money supply drops initially and then converges steadily to this new value with persistence equal to 0.6 . The size of the initial drop is set so as to match the trough in the response of money growth in Figure 2. We have to set one additional parameter, $\sigma_{m}$, in the model without working capital. Our strategy is as follows. We set this parameter such that all models match the initial response of the nominal interest rate. This led us to set $\sigma_{m}=8$. Panel (a) of the figure shows that the deep habits version of the model outperforms the other two versions. The cut in the money supply growth creates the recession which initiates the internal mechanism driving inflation upward in the deep habit version of the model. Note however that, given that we leave the monetary policy totally exogenous in this case, the hump in inflation dynamics is short lasting compared to the interest rate rule. The response of the nominal interest rate is also pretty well reproduced in the model as the positive response of the inflation rate reinforces the impact of the decline in money growth. As soon as standard habits are brought back into the model, inflation and the nominal interest rate are badly reproduced. In particular, inflation falls persistently in the aftermath of the shock. In order to further investigate this issue, we report in panel (b) the responses in the working capital version of the model. The model with nominal wage contracts with working capital performs better than its previous version as it is able to generate the positive hump on the interest rate. It however fails to mimic the response of inflation. The deep habits version does not perform as well as before in that inflation does not rise on impact and neither does the nominal interest rate, but the model gets the overall shape right.

Although, as aforementioned, Taylor rules can be thought of as good representation of monetary policy, we now investigate the robustness of the results to the use of a money growth rule instead, which may be thought of as a better representation of what happened during the pre-Volcker period. We consider a rule of the form

$$
\log \left(\gamma_{t}\right)=\varrho \log \left(\gamma_{t-1}\right)+(1-\varrho)\left(\log (\bar{\gamma})+\varpi_{y}\left(\log \left(y_{t}\right)-\log (\bar{y})\right)+\varpi_{\pi}\left(\log \left(\pi_{t}\right)-\log (\bar{\pi})\right)\right.
$$

where $\gamma_{t}$ is the gross rate of growth of money supply. $\varrho, \varpi_{\pi}$ and $\varpi_{y}$ are then set such that the model accounts for the dynamics of the inflation rate. We set $\varrho=0.5, \varpi_{\pi}=-2$ and $\varpi_{y}=-0.5$. Figure 15 reports the the implied dynamics. As can be seen from Panel (a), and for the same reasons as before, the deep habit model accounts for the dynamics of the three main variables under consideration, while the standard habit specification 
Figure 14: Robustness Analysis: Cutting Money Growth

(a) Benchmark model
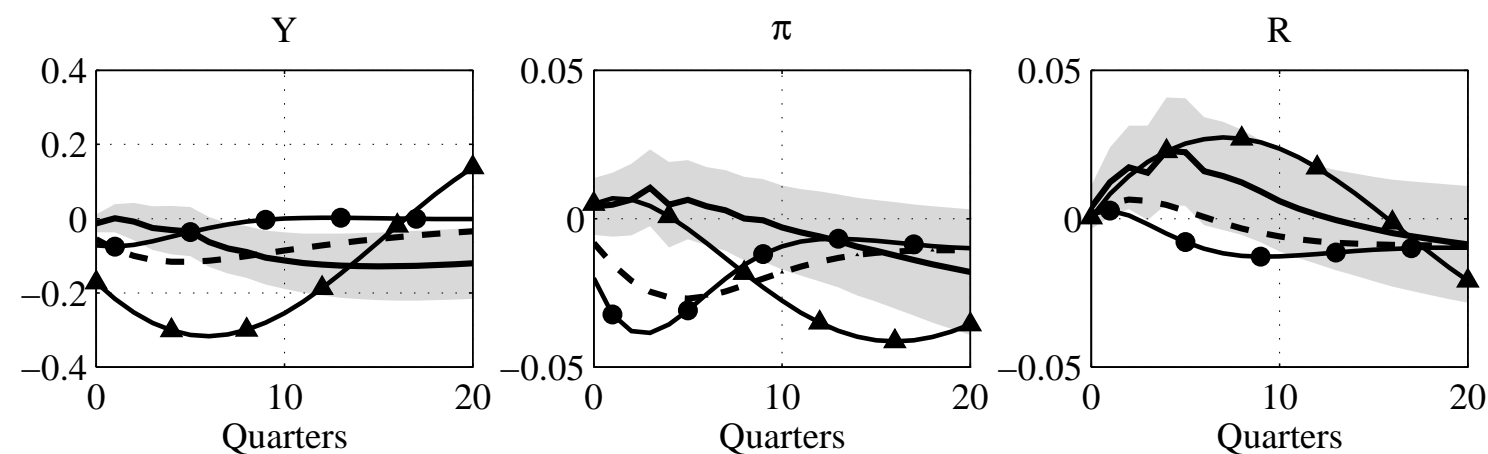

(b) Working capital model

Y

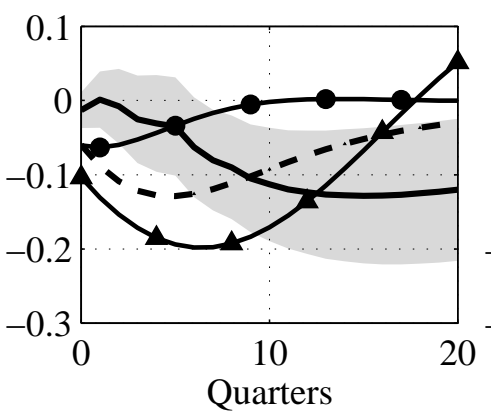

$\pi$

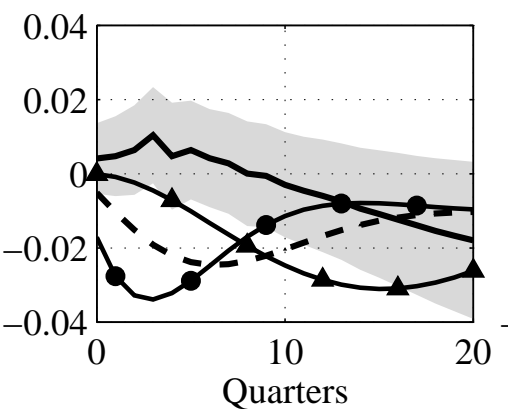

$\mathrm{R}$

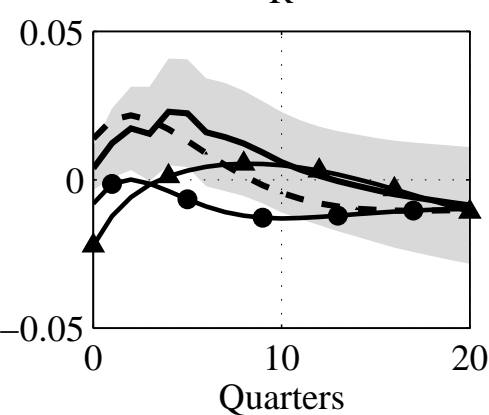

Note: $\longrightarrow$ Data; $\longrightarrow$ Deep Habits and sticky prices; $\longrightarrow$ Standard habits and sticky prices; - - Standard habits, sticky prices and sticky wages; Shaded area: $95 \%$ confidence interval. 
cannot match the facts. This occurs as long as the central bank is primarily concerned by inflation $\left(\varpi_{\pi}=-2\right)$. This result is therefore in line with our benchmark specification. In other words, the goal of monetary policy matters more than its actual implementation in the model. It is however worth noting that, contrary to the Taylor rule, the use of a money supply rule requires some output gap targeting $\left(\varpi_{y}=-0.5\right)$. Its main role in the model is to prevent the nominal interest rate to respond too much. Also note that the overall performance of the standard habit model does not improve under a money growth rule neither in the model without nor in the model with the working capital assumption (see Panel(b) of Figure 15).

This analysis clearly illustrates that disinflation periods are time in which inflation is the main — not to say the sole - concern of the central bank, which then becomes more aggressive with regard to inflation gaps. The way this disinflation policy is implemented does not seem to be critical, therefore indicating that most of our results are due to the countercyclicality of markups.

Real Frictions In this paragraph we want to stress the role of real frictions. The reason is clear. The persistence of the recession hinges on these mechanisms. Provided the latter are taken into account, the recession lasts for a sufficient number of period that firms can take advantage of a lower price elasticity to raise their prices in the short-run. In Panel (a) of Figure 16 we set a lower deep habit parameter $(b=0.5)$. In this case, the persistence of habits is not sufficient to let firms use price increases to limit profit losses. Indeed, the decrease in the price elasticity is not large and persistent enough and any increase in prices translates very soon into a decline in the demand for consumption goods. The model then fails to mimic the facts and starts resembling the standard habit specification.

Panel (b) and (c) of Figure 16 illustrate the role of real frictions in the model. In Panel (b) we replace capital adjustment costs by investment adjustment costs. In this case, the model still generates a recession, but that recession is less pronounced than with capital adjustment costs, and the model has difficulties generating hump shapes in inflation and the interest rate. ${ }^{26}$ The reason of this failure is clear. Investment adjustment costs essentially spread the changes in the level of investment over time, as this is changes in the level of investment that are penalized. This precludes investment from dropping and therefore limits the magnitude of the recession. The household devotes more of their income to consumption and can therefore improve their consumption smoothing, which limits the decline in the price elasticity. Overall, this limits the ability of firms to increase

\footnotetext{
${ }^{26}$ The model can still generate a positive hump shape in inflation and the interest rate provided the central bank is assumed to be more aggressive with regard to inflation.
} 
Figure 15: Robustness Analysis: Money Growth Rule

(a) Benchmark model
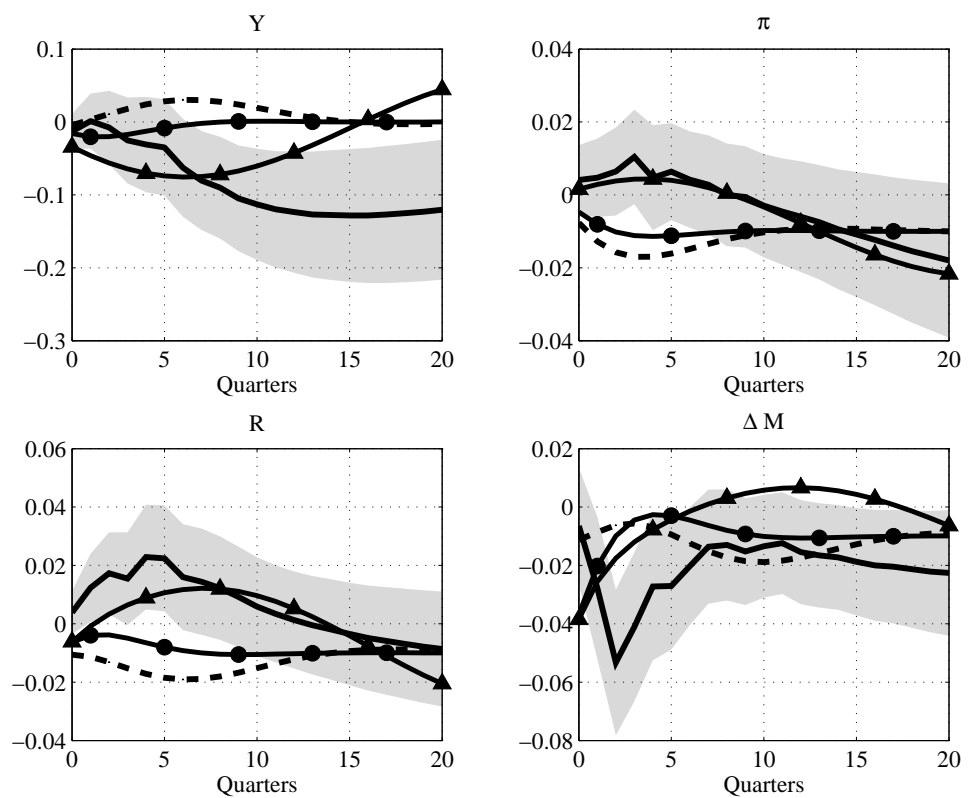

(b) Working capital model
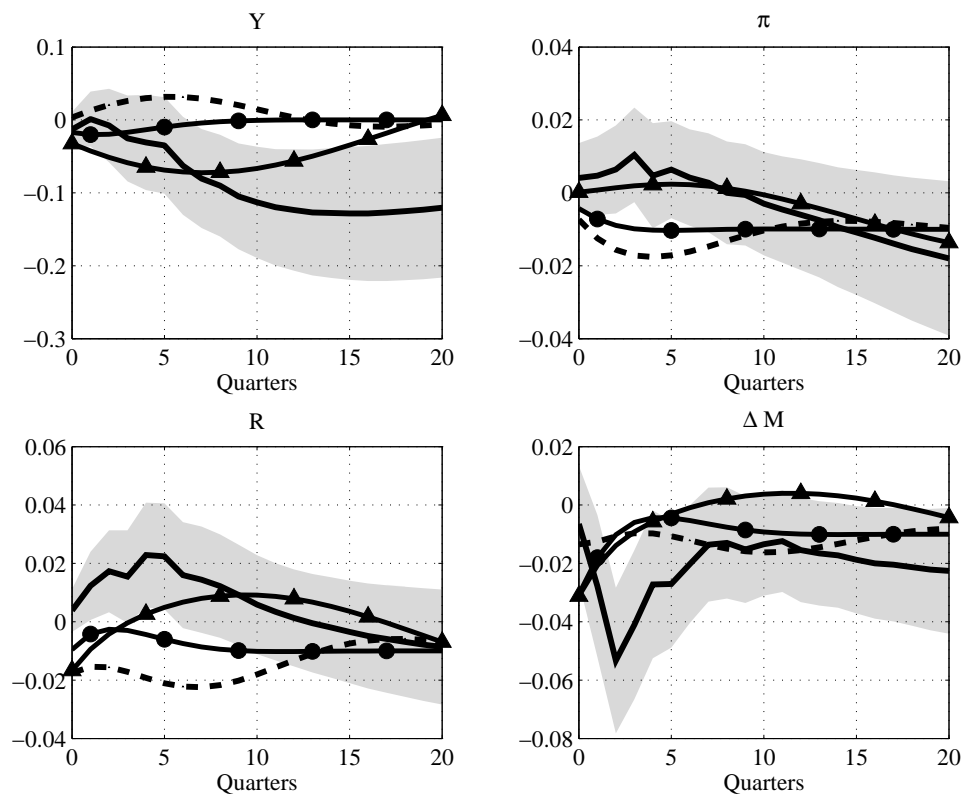

Note: — Data; — Deep Habits and sticky prices; —- Standard habits and sticky prices; - - Standard habits, sticky prices and sticky wages; Shaded area: $95 \%$ confidence interval. 
prices as a way to limit profit losses and therefore significantly dampens the hump in inflation and the interest rate. One way to circumvent this difficulty and keep investment adjustment costs is to drive $\varphi_{i}$ to much higher values $\left(\varphi_{i}=20\right)$. But in this latter case, investment does not react anymore and the model reduces to a model in which demand is essentially determined by consumption. The price elasticity mechanisms fully plays. In Panel (c) we shut down utilization. Once again the model cannot account for the facts. Indeed utilization acts as a way to magnify persistence in the model, and in particular the persistence of the recession. Once we shut down this channel, the recession does not last and is very weak. Therefore, the model lacks the two initial ingredients that are at the source of the decline in the price elasticity: (i) the deep recession and (ii) its persistence. The failure of the model then comes as no surprise.

Panel (d) of the model investigates a situation in which we get rid off the material goods in the production function. The model then fails to account for the facts. Indeed, material goods act as a way to smooth the real marginal cost in the economy as in this case it can be expressed as a linear combination of a time varying component, stemming from the Cobb-Douglas technology, and a constant component, pertaining to the material goods. ${ }^{27}$ This therefore limits the drop in the marginal cost and therefore enables prices to respond positively through the price elasticity channel. When the share of material goods is driven to zero, the marginal cost channel takes the upper hand and inflation responds negatively on impact. One way to recover a positive hump-shaped response of inflation is therefore to magnify the price elasticity channel by increasing the level of markups in steady states. For instance, raising markups to $65 \%$ the model generates responses similar to what obtains in our benchmark specification.

This sensitivity analysis illustrates the role of real frictions in accounting for disinflation episodes. Therefore, while we analyze totally different types of monetary policy shocks, we come to similar conclusions to those reached by Christiano et al. (2005) who argued that any model that aims at accounting for monetary facts has to possess strong enough real propagation mechanisms capable of protracting the effects of monetary policy.

\section{Conclusion}

This paper investigated the effects of disinflation policies on the macroeconomic variables that are the core of the monetary transmission mechanism. Using postwar US data and episode techniques, we identify disinflation shocks as shocks that drive the inflation rate

\footnotetext{
${ }^{27}$ Technically, we have $m c_{t}=s_{x}+\left(1-s_{x}\right) \frac{r_{k, t}^{\alpha} w_{t}^{1-\alpha}}{\alpha^{\alpha}(1-\alpha)^{1-\alpha}}$.
} 
Figure 16: Robustness analysis (Real Frictions)

(a) Low habits $(b=0.5)$
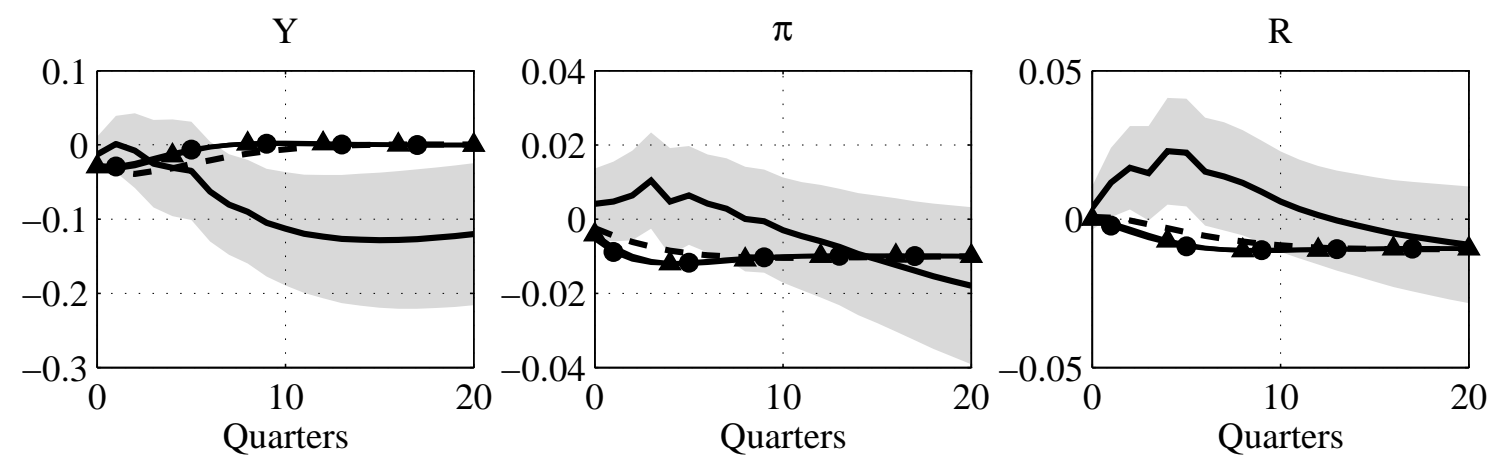

(b) Investment adjustment costs $\left(\omega=1, \varphi_{i}=2.5\right)$
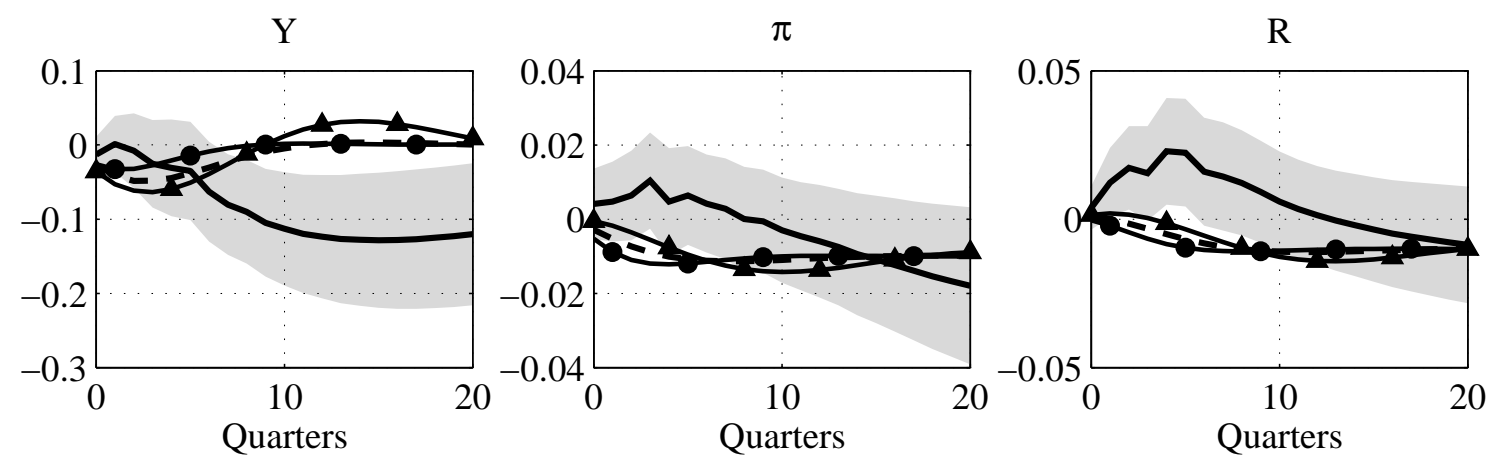

(c) Utilization $\left(\sigma_{z} \rightarrow \infty\right)$
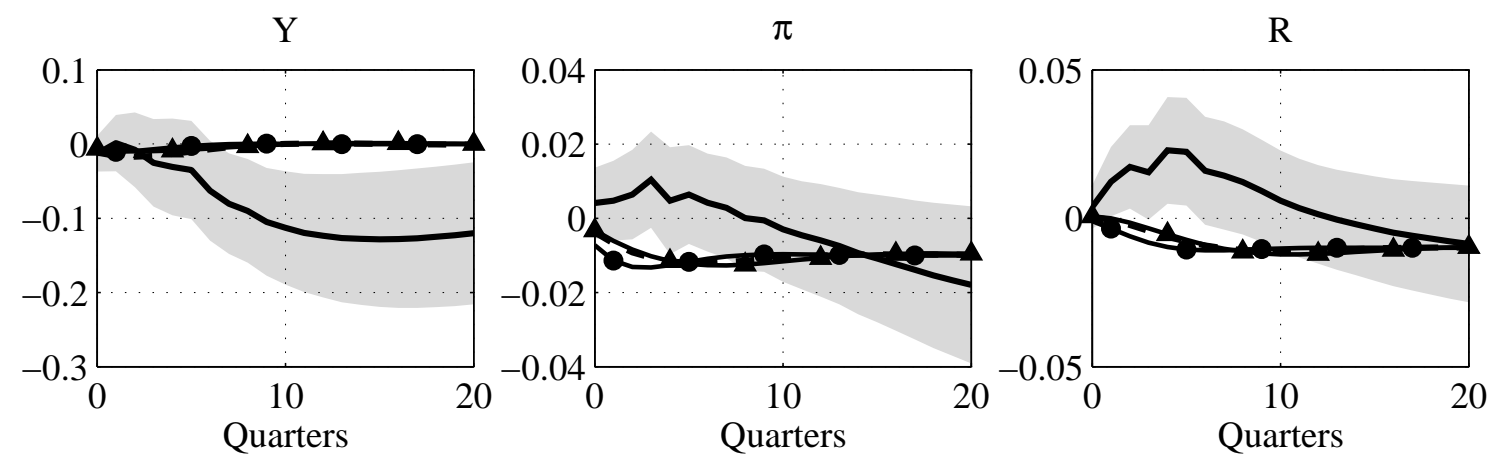

(d) No material goods $\left(s_{x}=0\right)$

Y

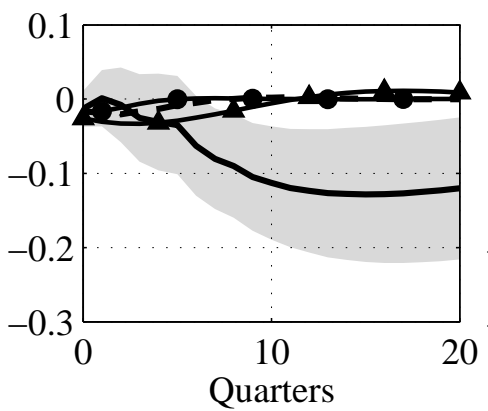

$\pi$

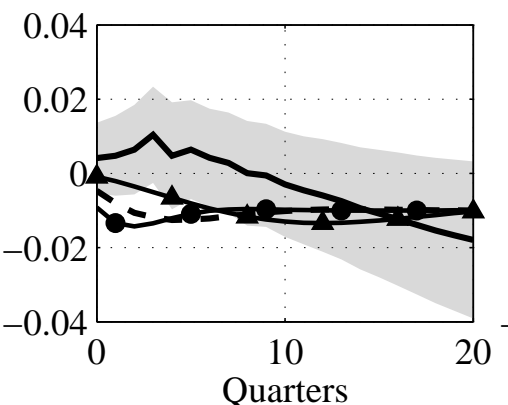

$\mathrm{R}$

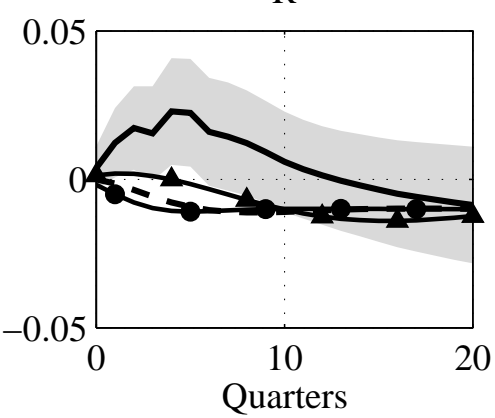

Note: —Data; — Deep Habits and sticky prices; —- Standard habits and sticky prices; - - Standard habits, sticky prices and sticky wages; Shaded area: $95 \%$ confidence interval. 
to a lower level in the long-run. We find that in the immediate aftermath of a disinflation policy, the economy enters a persistent recession. The inflation rate increases above its long-run level and exhibits a positive hump-shaped response for about 10 quarters. A similar pattern is found for the nominal interest rate, which responds even more strongly in the short-run. We then assess whether the standard new Keynesian model, as exemplified in Christiano et al. (2005), Altig et al. (2005) or Smets and Wouters (2005) can account for these facts.

We find that, in a reasonably calibrated version of the model, the standard new Keynesian model fails to mimic the dynamics of both inflation and the nominal interest rate. The reason is that the model generates insufficiently countercyclical markups. We then modify the model along the lines recently advocated by Ravn et al. (2006) and introduce a deep habits phenomenon. The model is then able to match the joint dynamics of inflation and the nominal interest rate, and outperforms a sticky price and a sticky price-sticky wage version of the standard new Keynesian model in terms of output, inflation and interest rate dynamics. The reason of this success is that the deep habit model generates countercyclical markups that drive inflation and the interest rate upward during the recession. Another finding of the model is that, as already argued in Christiano et al. (2005), additional real frictions are needed to get the dynamics of macroeconomic variables right. For instance, shutting down adjustment costs and/or variable utilization leads to a worsening of the results. 


\section{References}

Abel, A., Asset Prices under Habit Formation and catching up with the Joneses, American Economic Review, Papers and Proceedings, 1990, 80 (2), 38-42.

Altig, D., L. Christiano, M. Eichenbaum, and J. Linde, Firm-Specific Capital, Nominal Rigidities and the Business Cycle, Working paper 11034, NBER, Cambridge (MA) 2005.

Ball, L., What determines the sacrifice ratio?, in N.G. Mankiw, editor, Monetary Policy, Chicago, IL: University of Chicago Press, 1994.

, Disinflation and Imperfect Credibility, Journal of Monetary Economics, 1995, 35 (1), $5-24$.

Basu, S. and J.G. Fernald, Constant Returns and Small Markups in U.S. Manufacturing, International Finance Discussion Paper 483, Governors Federal Reserve System, Washington, DC 1994.

Beaudry, P. and A. Guay, What Do Interest Rates Reveal about the Functioning of Real Business Cycle Models?, Journal of Economic Dynamics and Control, 1996, 20, $1661-1682$.

Blanchard, O.J. and D. Quah, The Dynamic Effects of Aggregate Demand and Supply Disturbances, American Economic Review, 1989, 79 (4), 655-673.

Boldrin, M., L.J. Christiano, and J.D.M. Fisher, Habit Persistence, Asset Returns and the Business Cycle, American Economic Review, 1999, 91 (1), 149-166.

Bordo, M., C. Erceg, A. Levin, and R. Michaels, Three Great American Disinflations, mimeo, Federal Reserve Board 2006.

Burnside, C., M. Eichenbaum, and J.D.M. Fisher, Fiscal Shocks and Their Consequences, Journal of Economic Theory, 2004, 115 (1), 89-117.

Cecchetti, S.G., Comment to Ball, in N.G. Mankiw, editor, Monetary Policy, Chicago, IL: University of Chicago Press, 1994.

and R. Rich, Structural Estimates of the US Sacrifice Ratio, Journal of Business and Economic Statistics, 2001, 19 (4), 416-427.

Christiano, L.J. and J.D.M. Fisher, Stock Market and Investment Goods Prices: Implications for Macroeconomics, Working Paper 10031, NBER, Cambridge (MA) 2003. 
_, M. Eichenbaum, and C.L. Evans, Monetary Policy Shocks: What Have we Learned and to What End?, in M. Woodford and J. Taylor, editors, Handbook of Macroeconomics, North-Holland, 1999, chapter 3.

__ _ Policy, Journal of Political Economy, 2005, 113 (1), 1-45.

Clarida, R., J. Galí, and M. Gertler, The Science of Monetary Policy: A New Keynesian Perspective, Working Paper 7147, NBER, Cambridge (MA) 1999.

Edelberg, W., M. Eichenbaum, and J.D.M. Fisher, Understanding the Effects of a Shock to Government Purchases, Review of Economic Dynamics, 1999, 2 (1), 166-206.

Eichenbaum, M., Comments on 'Interpreting the macroeconomic time series facts: The effects of monetary policy', European Economic Review, 1992, 36 (5), 1001-1012. and J.D.M. Fisher, Fiscal Policy in the Aftermath of 9/11, Journal of Money, Credit and Banking, 2005, 37 (1), 1-22.

Erceg, C.J. and A.T. Levin, Imperfect Credibility and Inflation Persistence, Journal of Monetary Economics, 2003, 50 (4), 915-944.

, D.W. Henderson, and A.T. Levin, Optimal Monetary Policy with Staggered Wage and Price Contracts, Journal of Monetary Economics, 2000, 46 (2), 281-313.

Filardo, A.J., New Evidence on the output Cost of Fighting Inflation, Economic Review, Federal Reserve Bank of Kansas City 1998.

Francis, N. and M.T. Owyang, Monetary Policy in a Markov-Switching Vector ErrorCorrection Model: Implications for the Cost of Disinflation and the Price Puzzle, Journal of Business and Economic Statistics, 2005, 23 (3), 305-313.

Galí, J., Technology, Employment, and the Business Cycle: Do Technology Shocks Explain Aggregate Fluctuations?, American Economic Review, 1999, 89 (1), 249-271.

Hall, R., The Relation between Price and Marginal Cost in the US Industry, Journal of Political Economy, 1988, 96 (5), 921-948.

Hamilton, J.D., What is an Oil shock?, Journal of Econometrics, 2003, 113 (2), 363-398.

Hoover, K.D. and S.J. Perez, Post Hoc Ergo Propter Once More: an evaluation of 'Does Monetary Policy Matter?' in the Spirit of James Tobin, Journal of Monetary Economics, 1994, 34 (1), 47-73. 
Jaimovich, N. and S. Rebelo, Can News About the Future Drive the Business Cycle?, Working Paper 12537, NBER, Cambridge (MA) 2006.

Jorgenson, D., F.M. Gollop, and B.M. Fraumeni, Productivity and U.S. Economic Growth, Cambridge (MA): Harvard University Press, 1987.

Kashyap, A.K., J.C. Stein, and D.W. Wilcox, Monetary Policy and Credit Conditions: Evidence from the Composition of External Finance, American Economic Review, 1993, 83 (1), 78-98.

Leeper, E.M., Narrative and VAR approaches to monetary policy: Common identification problems, Journal of Monetary Economics, 1997, 40 (3), 641-657.

and J.E. Roush, Putting "M" back in Monetary Policy, Journal of Money, Credit and Banking, 2003, 35 (6), 1217-1256.

Lucas, R.E. and E.C. Prescott, Investment under Uncertainty, Econometrica, 1971, 39 (5), 659-681.

Morrison, C.J., Market Power, Economic Profitability and Productivity Growth Measurement: An Integrated Structural Approach, Working Paper 3355, NBER, Cambridge (MA) 1990.

Oliner, S.D. and G.D. Rudebusch, 'Is There a Broad Credit Channel for Monetary Policy?, Federal Reserve Bank of San Francisco Review, 1996, 1, 3-13.

Owyang, M.T. and G. Ramey, Regime Switching and Monetary Policy Measurement, Journal of Monetary Economics, 2004, 51 (8), 1577-1597.

Phelps, E.S., Disinflation wothout Recession: Adaptive Guideposts and Monetary Policy, Weltwrtschaftliches Archiv. Bank, 1978, 114.

Ravn, M., S. Schmitt-Grohe, and M. Uribe, Deep Habits, Review of Economic Studies, 2006, 73 (1), 195-218.

Romer, C. and D. Romer, Does Monetary Policy Matter? A New Test in the Spirit of Friedman and Schwartz, NBER Macroeconomics Annual, 1989, 4, 121-170.

_ _ and _ Monetary policy matters, Journal of Monetary Economics, 1994, 34 (1), 75-88.

Rotemberg, J. and M. Woodford, Dynamic General Equilibrium Models with Imperfectly Competitive Product Markets, in T. Cooley, editor, Frontiers of Business Cycle Research, Princeton, New-Jersey: Princeton University Press, 1995, chapter 9. 
and __ The Cyclical Behavior of Prices and Costs, in J.B. Taylor and M. Woodford, editors, Handbook of Macroeconomics, Vol. 1b, Amsterdam, NL: Elsevier Science, 1999, chapter 16 .

Rotemberg, J.J. and M. Woodford, An optimization-based econometric framework for the evaluation of monetary policy, in B.S. Bernanke and J.J. Rotemberg, editors, NBER Macroeconomics Annual, Cambridge (MA): MIT Press, 1997.

Shapiro, M.D., Federal Reserve policy: cause and effect, in N.G. Mankiw, editor, Monetary Policy, Chicago: University of Chicago Press, 1994, pp. 307-334.

Sims, C.A., Interpreting the Macroeconomic Time Series Facts: The effects of Monetary Policy, European Economic Review, 1992, 36 (5), 975-1000.

Smets, F. and R. Wouters, Comparing shocks and frictions in US and euro area business cycles: a Bayesian DSGE approach, Journal of Applied Econometrics, 2005, 20 (2), $161-183$.

Taylor, J.B., An Historical Analysis of Monetary Policy Rules, in J.B. Taylor, editor, Monetary Policy Rules, Chicago, IL: University of Chicago Press, 1999. 
Figure 17: Historical decomposition of episodes 1-4

(a) 1966:II
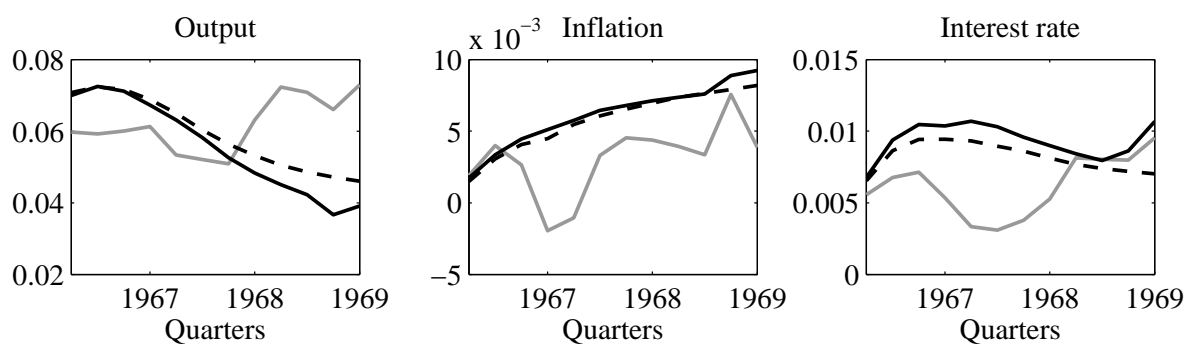

(b) 1974:II
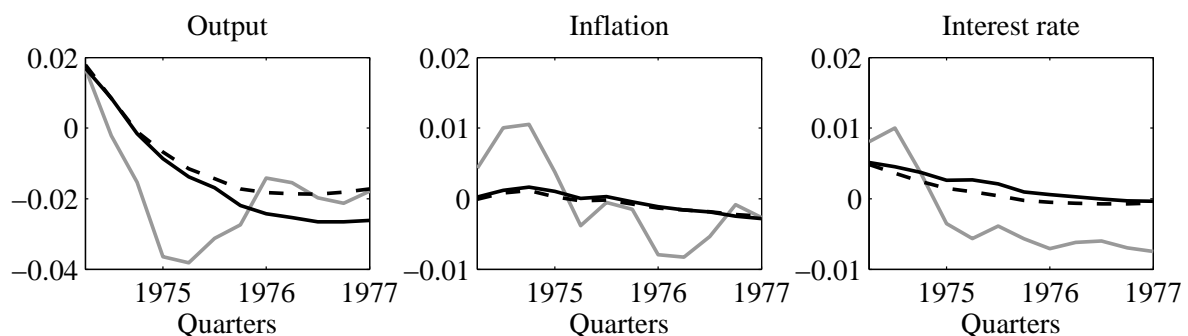

(c) $1979: \mathrm{IV}$
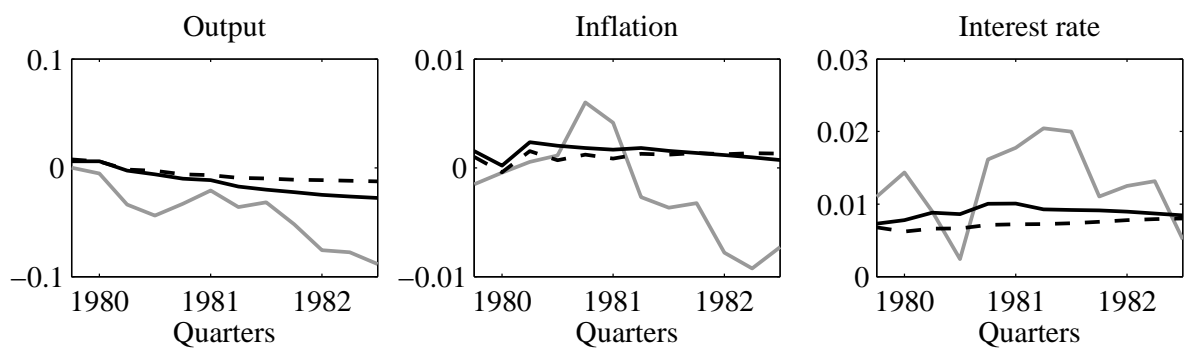

(d) 2000:I
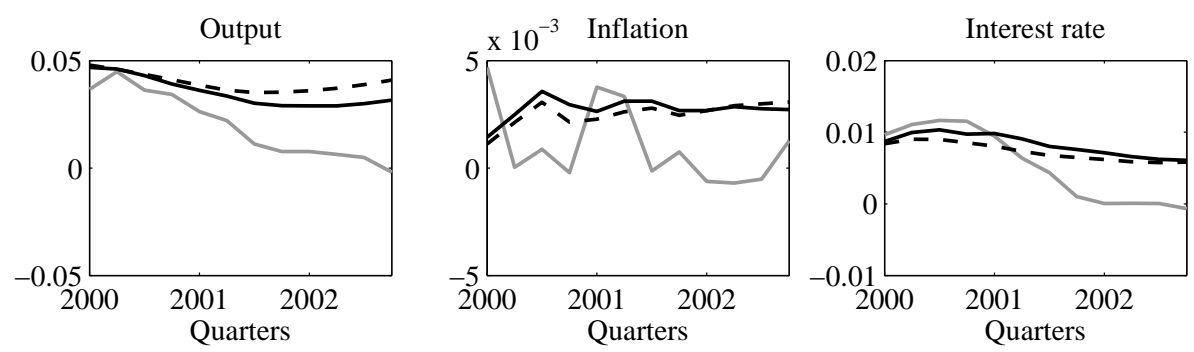

Note: gray plain line: Actual data, dark plain line: Forecast with episode, dark dashed line: Forecast without episode. 
Figure 18: Response to disinflation shock (Blanchard and Quah identification)
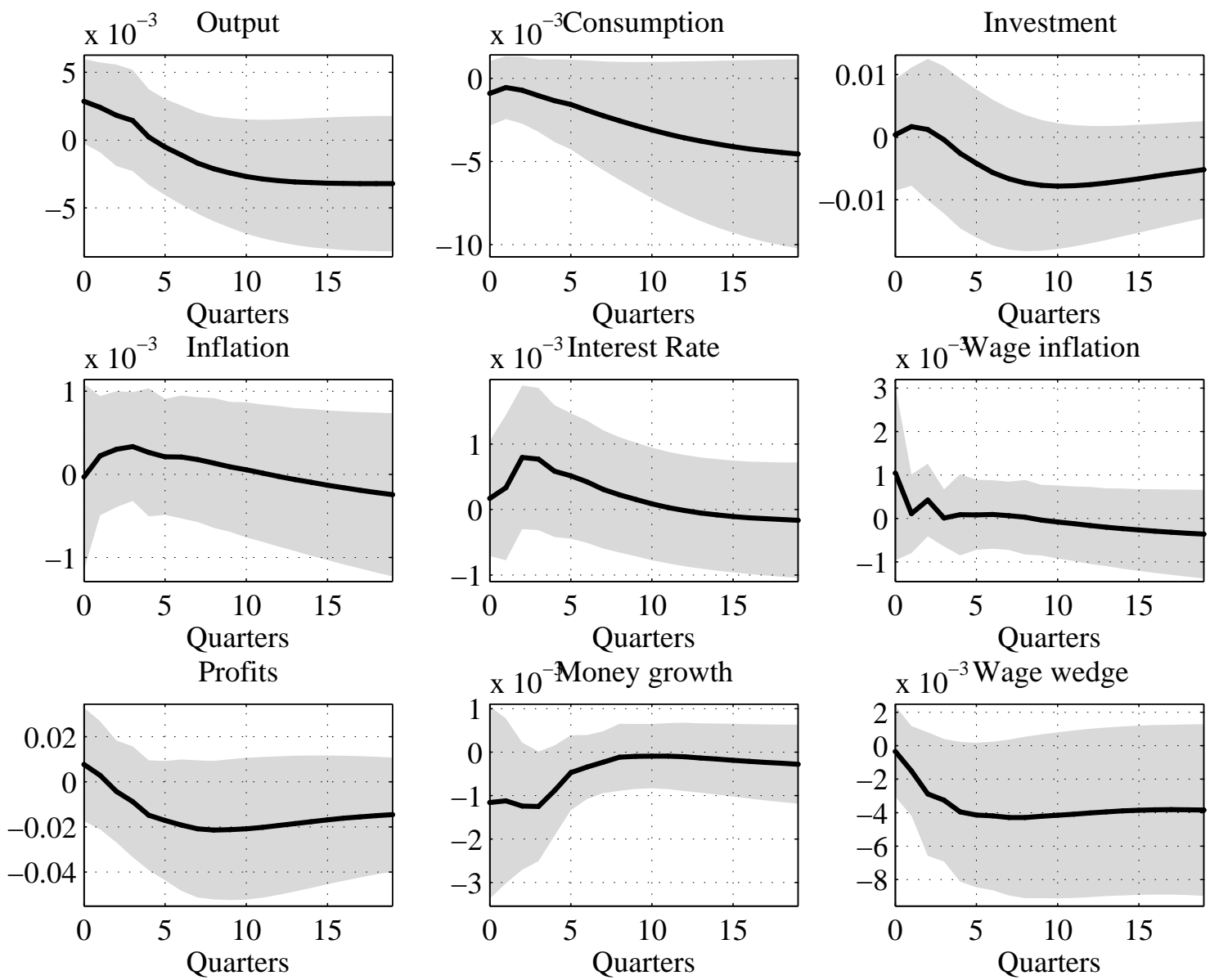